\title{
The effect of food preparation on the bioavailability of carotenoids from carrots using intrinsic labelling
}

\author{
Abdollah Ghavami, W. Andy Coward† and Les J. C. Bluck* \\ MRC Human Nutrition Research, Elsie Widdowson Laboratory, Fulbourn Road, Cambridge CB1 9NL, UK \\ (Submitted 10 December 2010 - Final revision received 13 July 2011 - Accepted 13 July 2011 - First published online 19 September 2011)
}

\begin{abstract}
A strategy to reduce the incidence of vitamin A deficiency is to improve precursor bioavailability from meals. Since vitamin A precursors are fat-soluble, we noted that carotenoids are more easily absorbed from food if prepared in such a way that the food matrix containing provitamin A ( $\beta$-carotene) is sufficiently fat rich. To quantify this effect, we have developed a stable isotope methodology. By regular watering with ${ }^{2} \mathrm{H}$-labelled water, we were able to produce several $\mathrm{kg}$ of intrinsically labelled carrots, with carotenoids labelled to $0.63 \%$ excess ${ }^{2} \mathrm{H}$. These were divided into $100 \mathrm{~g}$ portions and fed to a small group of healthy subjects both raw and stir-fried. To normalise for inter-individual variation in absorption and subsequent metabolism, small quantities of extrinsically ${ }^{13} \mathrm{C}$-labelled $\beta$-carotene and ${ }^{2} \mathrm{H}$-labelled retinol acetate were also incorporated into the meal. After ingestion of the carrots, blood lipids were monitored for a period of $3 \mathrm{~d}$ in order to determine the kinetics of $\beta$-carotene and retinol. From kinetic data, it was estimated that the bioavailability of carrot-derived $\beta$-carotene compared with pure $\beta$-carotene was about $11 \%$ for raw carrots, but $75 \%$ when the carrots were stir-fried. Conversely, there was a slight reduction in the bioconversion to retinol from $\beta$-carotene when the latter was derived from the stir-fried meal compared with that from raw carrots. When these two factors are combined, the yield of retinol from the carotene in carrots was found to be enhanced by a factor of 6.5 by stir-frying.
\end{abstract}

\section{Key words: Stable isotopes: Vitamin A bioavailability: Intrinsic labelling}

It has been estimated that, worldwide, nearly three million children under the age of 5 years have clinical symptoms (night blindness and xerophthalmia) of vitamin A deficiency (VAD), and more than 200 million people are considered vitamin $\mathrm{A}$ deficient ${ }^{(1)}$. In more than half of all countries, VAD is a significant public health issue, particularly in Africa and parts of Asia, where, according to the WHO, it causes blindness in more than 250000 children every year. Subclinical VAD compromises immune function ${ }^{(2)}$ and is a major contributor to mortality in affected adults and children.

Strategies to combat VAD have broadly followed three main themes ${ }^{(2,3)}$ : supplementation; fortification; dietary improvement. The latter approach is probably the most sustainable locally and, therefore, the best long-term method of controlling the prevalence of $\mathrm{VAD}$, and eventually eliminating it. However, it will fail if local agriculture cannot produce foods with adequate vitamin A or precursor content, or if vitamin A in the ingested foodstuff is not optimally absorbed and utilised by the body.

Vitamin A and its precursor carotenoids are fat-soluble; sources from foods of animal origin are in the form of retinyl esters (principally palmitate), while vegetables provide provitamin A principally in the form of $\beta$-carotene, although $\alpha$-carotene, $\gamma$-carotene and $\beta$-cryptoxanthin also make a contribution. These compounds exit the stomach and enter the small intestine in bulk liquid droplets. The retinyl esters are enzymatically hydrolysed to retinol, and then absorbed by passive diffusion into the enterocytes along with the carotenoid sources of vitamin A. In the enterocytes, retinol is re-esterified to palmitate, incorporated into chylomicrons and secreted into the lymphatic system. The carotenoids, on the other hand, may be directly incorporated into chylomicrons, or they may be cleaved to form retinyl esters before incorporation. Some of the carotenoids remain in the enterocytes and are lost as the cells are removed. Because of this complex metabolism, less retinol is derived from the carotenoids than might be expected from stoichiometric considerations of the molecular structure. The ratio of the amount of retinol obtained for normal physiological function to the quantity of $\beta$-carotene ingested is termed bioavailability ${ }^{(4)}$. In the case of vitamin A derived from the carotenoids, the bioavailability clearly incorporates a term describing the bioconversion (the definitions of bioavailability and

Abbreviations: ACN, acetonitrile; RE, retinol equivalent; VAD, vitamin A deficiency.

*Corresponding author: Dr L. J. C. Bluck, fax +44 1223 437515, email les.bluck@mrc-hnr.cam.ac.uk

†Deceased on 3 November 2007 
bioconversion are not consistent within the literature. Some authors used bioconversion as a blanket term to cover both availability and subsequent conversion ${ }^{(5,6)}$ ). The bioavailability of vitamin A from a food depends on a number of factors including the species of carotenoid from which it is derived, the chemical form (e.g. free or as esters) in which that carotenoid is present, the amount of carotenoid present in the food, the matrix in which it exists, the presence of other food constituents which enhance or inhibit absorption, and the nutritional status health, and genetic profile of the subject. In general, it is not expected that these factors will operate independently, and considerable interactions are likely to determine the bioavailability of vitamin A from a particular carotenoid in a given subject.

Given all of these factors, probably the simplest manipulation to improve vitamin A bioavailability from carotenoids is meal preparation. The choice of vegetable may be restricted by the local agricultural conditions, but its use as a source of vitamin A can be optimised by considering the way in which it is prepared for the table. It has been noted that both provitamin A carotenoids and vitamin A itself are fatsoluble, and therefore it is reasonable to predict that carotenoids are more likely to be utilised if they are presented in an environment with sufficient fat to assist in their uptake. On this basis, it has been predicted and demonstrated that fried vegetables are better sources of vitamin A than raw ones, whereby the adoption of a diet where a higher fraction of the vegetables is fried might be beneficial in populations at risk of VAD. The object of the present study was to compare the bioavailability of vitamin A from raw and stir-fried carrots using stable isotope tracers. In order to ensure that true bioavailability from the vegetable matrix was determined, it was decided that the carrots should be intrinsically labelled, and this was simply achieved by irrigating them during growth with ${ }^{2} \mathrm{H}$-enriched water. The carrots were then prepared for eating, either raw or stir-fried, and the kinetics of the labelled carotenoids and retinol established in the plasma of healthy volunteers. To control for inter- and intra-individual variation, we gave oral doses of synthetic extrinsic ${ }^{13} \mathrm{C}$-labelled $\beta$-carotene and $\left[{ }^{2} \mathrm{H}_{4}\right]$ retinol simultaneously with the carrot meal.

\section{Materials and methods}

\section{Reagents and equipment}

Reagents and apparatus were obtained from the following suppliers:

Aldrich Chemical Company Inc., Milwaukee, WI, USA ${ }^{2} \mathrm{H}_{2} \mathrm{O}(99 \%)$.

ARC Laboratories BV, Apeldoorn, The Netherlands $8,8^{\prime}, 9,9^{\prime}, 10,10^{\prime}, 11,11^{\prime}, 12,12^{\prime}, 13,13^{\prime}, 14,14^{\prime}, 15,15^{\prime}, 19,19^{\prime}, 20,20^{\prime}$ $\left[{ }^{13} \mathrm{C}_{20}\right] \beta$-carotene, (all-E)- $\left(\left[{ }^{13} \mathrm{C}_{20}\right] \beta\right.$-carotene); 10,19,19,19$\left[{ }^{2} \mathrm{H}_{4}\right]$ retinol acetate $\left(\left[{ }^{2} \mathrm{H}_{4}\right]\right.$ retinol acetate $)$.

CaroteNature GmbH, Lupsingen, Switzerland - $\alpha$-carotene, all-trans; $\beta$-cryptoxanthin.

Fisher Scientific UK Limited, Leicestershire, UK - acetonitrile (ACN, HPLC grade); magnesium carbonate; MeOH (HPLC grade).

IKA Werke GmbH, Staufen, Germany - homogeniser, Ultra Turrax model T25.
Riedel-de Haën, Seelze, Germany - absolute ethanol.

Sigma Aldrich Limited, Dorset, UK - butylated hydroxytoluene; (all- $E$ )- $\beta$-carotene, synthetic; ethyl- $\beta$-apo- $8^{\prime}$-carotenoate; petroleum diethyl ether $\left(35-60^{\circ} \mathrm{C}\right.$ fraction) spectrophotometric grade; platinum (IV) oxide; retinol acetate, all-trans, synthetic.

VWR International Limited, Dorset, UK - dichloromethane (HPLC grade); $n$-heptane (HPLC grade); hexane (HPLC grade); tetrahydrofuran.

\section{Intrinsic labelling of carrots}

${ }^{2} \mathrm{H}_{2} \mathrm{O}(99 \%)$ was diluted with local tap water to give a $2 \%$ solution. Carrot seeds (F1 Healthmaster Daucus carota, Autumn King) were sown in Levington potting compost and grown in an unheated greenhouse. Not $<1$ week after germination, the hole in the bottom of the pot was taped over, and the top covered with a plastic bag, which had been pierced with a small hole. These measures were adopted to minimise the rate of water evaporation while allowing some transpiration to occur. The plants were watered daily with ${ }^{2} \mathrm{H}_{2} \mathrm{O}$ for 7 weeks, and then the carrots were harvested.

The carrots were washed and the ends were cut, before being peeled and then blanched for $6 \min ^{(7,8)}$, after which they were plunged into ice water to halt the cooking process. The carrots were then homogenised in a food processor, divided into portions of $110 \mathrm{~g}$, which were individually wrapped in $\mathrm{Al}$ foil and placed in plastic bags for storage at $-20^{\circ} \mathrm{C}$ until required.

\section{Carotenoid analysis of carrots}

The carotenoid content of the grown contents was determined by HPLC of a lipid extract (Fig. 1), where the sample processing procedure is divided into segments A-I, as follows:

(A) The sample extraction was achieved using the method described by Hart \& $\operatorname{Scott}^{(9)}$. Duplicate samples $(10 \mathrm{~g})$ of carrot were homogenised together with $1 \mathrm{~g} \mathrm{MgCO}_{3}$ and $50 \mathrm{ml}(1: 1, \mathrm{v} / \mathrm{v})$ tetrahydrofuran-MeOH containing $165 \mu \mathrm{g}$ (all-E)-ethyl- $\beta$-apo- $8^{\prime}$-carotenoate as an internal standard.

(B) The dried extract was dissolved in $20 \mathrm{ml}$ dichloromethane, and a $200 \mathrm{ml}$ aliquot diluted in $10 \mathrm{ml}$ mobile phase, ACN-MeOH-dichloromethane (44:44:12\%, $\mathrm{v} / \mathrm{v} / \mathrm{v})$. Isocratic separation was achieved using a Waters Alliance 2695 Separation Module equipped with a $4.6 \mathrm{~mm} \times 100 \mathrm{~mm}$ reverse-phase $\mathrm{C}_{18}$ cartridge column with a $3.5 \mu \mathrm{m}$ particle size and a $10 \mathrm{~nm}$ pore size (Waters UK Ltd, Elstree, Herts, UK). The column was thermostatically controlled at $23 \cdot 0 \pm 0 \cdot 1^{\circ} \mathrm{C}$ for the stability of retention time. Detection was accomplished by a Waters 996 photodiode array (Waters Limited) operating in the range of $280-480 \mathrm{~nm}$. Quantification was achieved by calibration with a standard solution containing $\alpha$-carotene, $\beta$-carotene and $\beta$-cryptoxanthin at concentrations of the order of $0.4 \mu \mathrm{mol} / \mathrm{l}$, with retinol acetate and ethyl- $\beta$-apo- $8^{\prime}$-carotenoate as internal standards. 


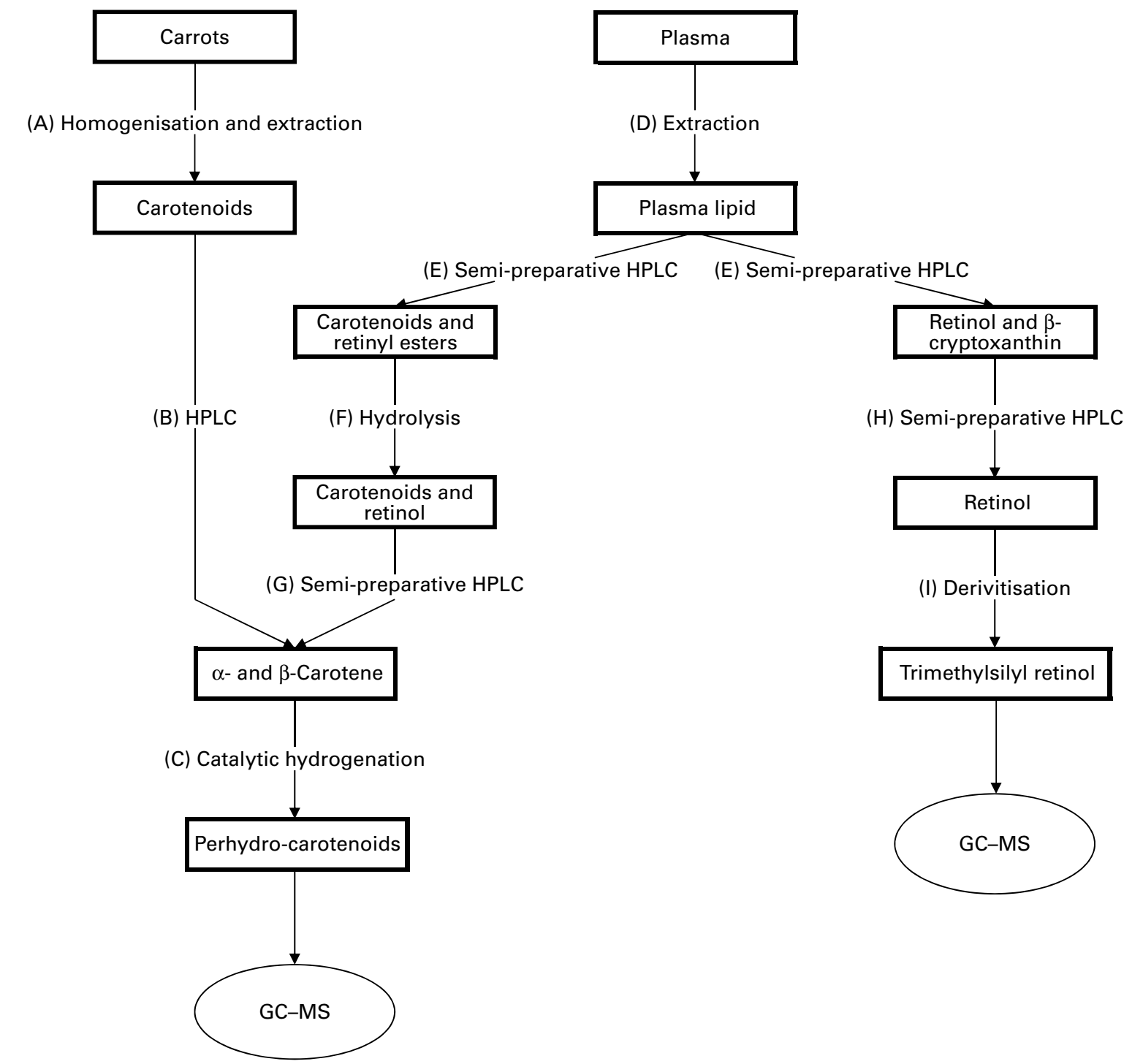

Fig. 1. Schematic diagram illustrating the key steps taken to extract carotenoids from carrots and carotenoids and retinol from blood plasma, for their eventual quantitative measurement on HPLC and qualitative measurement on GC-MS.

(C) For the isotopic investigation, the $\beta$-carotene fraction was collected and dried under $\mathrm{N}_{2}$ at room temperature. The perhydro derivative was then prepared based on published methods ${ }^{(10,11)}$, by dissolving the residue in $0.5 \mathrm{ml}$ hexane and transferring to sample vials containing a platinum (IV) oxide catalyst. The vials were flushed through and filled with hydrogen at 2 bar, and then left in a heating block at $65^{\circ} \mathrm{C}$ in the dark for $16 \mathrm{~h}$. The tubes were washed three times with $200 \mu \mathrm{l}$ hexane, which was then transferred to amber silanised GC vials, dried under $\mathrm{N}_{2}$ at room temperature, and redissolved in $10 \mu \mathrm{l}$ hexane before analysis.

GC/MS was performed using a 6890 GC coupled to a 5973 mass-selective detector (Agilent Technologies, West Lothian, UK) with an on-column injector. The injector was fitted with an Agilent $1.0 \mathrm{~m} \times 0.530 \mathrm{~mm}$ deactivated fused silica retention gap. The retention gap was connected via a metal union to a $15 \mathrm{~m} \times 0.25 \mathrm{~mm}$ (inner diameter) fused silica capillary column coated with a DB1-MS stationary phase $(0.25 \mu \mathrm{m}$ in thickness; J\&W Scientific, Agilent Technologies UK Ltd, Stockport, Cheshire, UK). Chromatographic separation was achieved with a four-stage temperature programme: $60-265^{\circ} \mathrm{C}$ at $25^{\circ} \mathrm{C} / \mathrm{min}$, followed by $265-300^{\circ} \mathrm{C}$ at $10^{\circ} \mathrm{C} / \mathrm{min}$, before a 4 min isothermal step. Finally, the column was ramped to $325^{\circ} \mathrm{C}$ over a final minute to complete elution of remaining materials. The isotopomer ratios were measured in selected ion monitoring mode of the mass cluster 558-562 m/ $z$ using the peak-fitting method of Bluck \& Coward ${ }^{(12)}$.

Hydrogenation transforms the carotene, $\mathrm{C}_{40} \mathrm{H}_{56}$ (molecular weight 536), to the perhydro compound $\mathrm{C}_{40} \mathrm{H}_{78}$ (molecular weight 558), adding twenty-two hydrogen atoms (and in the process destroying the chiral centre that distinguishes $\alpha$ - from $\beta$-carotene). The cracking pattern of the molecular cluster can be analysed by assuming that the molecule is made up of two species of hydrogen, one comprising fifty-six sites with fractional abundance $F_{\mathrm{a}}$, and the other twenty-two sites at abundance $F_{\mathrm{b}}$, in addition to the carbon with abundance $F_{\mathrm{C}}$. 
Elementary permutation and combination theory allows the isotopomer distribution to be calculated ${ }^{(13)}$ to obtain expressions for the mass ratios 559/558 $(M+1), 560 / 598(M+2)$ and 561/ $598(M+3)$ in terms of the elemental fractional abundances (see Appendix 1). It is then assumed that the carbon and the b-hydrogens are at natural abundance $\left(F_{\mathrm{C}}=0.0111\right.$, $\left.F_{\mathrm{b}}=0.00015\right)^{(14)}$, and a value for $F_{\mathrm{a}}$ obtained by least squares fitting the ratios to the experimentally observed values.

\section{In vivo determination of bioavailability of carotenoids from carrots}

Subjects. A total of five healthy subjects were recruited to the study by advertisement. The study was conducted according to the guidelines laid down in the Declaration of Helsinki and all procedures involving human subjects were approved by the Cambridge Local Research Ethics Committee (02/069 approved on 2 April 2002) and informed written consent was obtained from all subjects. Potential recruits were screened at an interview using a medical questionnaire, and excluded if they were smokers or heavy users of alcohol, taking nutrient supplements containing vitamin A, suffering from significant renal, liver or respiratory disease or had any disorder, which might interfere with gastrointestinal function, or had been diagnosed with diabetes. Women who were pregnant or intending to become pregnant during the course of the study were also excluded, as were those who were breast-feeding.

Overall protocol. The study was intended as a proof of principle to determine a methodology for investigating the effects of cooking method and overall meal composition on the bioavailability of vitamin A from a particular meal component. For the purposes of the study, a comparison of the bioavailability of raw and stir-fried carrots was made, following the hypothesis that the lipid-soluble carotenoids would be more bioavailable from a meal matrix containing added fat in the form of a cooking vegetable oil. The subjects were therefore asked to participate in two sessions of testing, separated by a period of 4 weeks. On the first occasion, they were randomly assigned to consume a test meal of either raw or stir-fried carrots, with the alternative meal being given on the second visit.

Meal study protocol. The subjects were asked to attend the volunteer suite at Human Nutrition Research (HNR) on the morning of the 1st day of the meal study having fasted for $12 \mathrm{~h}$. Their height and weight were recorded to the nearest $0.1 \mathrm{~kg}$ and $0.01 \mathrm{~m}$, and $10 \mathrm{ml}$ of basal blood samples were collected. Blood samples in the present study were taken by venepuncture into $9 \mathrm{ml}$ and $4.9 \mathrm{ml} \mathrm{S}$-Monovette lithium heparin tubes (Sarstedt Ltd, Beaumont Leys, Leics, UK). The subject then consumed a single bolus dose of $100 \mathrm{~g}$ of the intrinsically labelled carrots (either raw or stir-fried in $10.5 \mathrm{ml}$ groundnut oil), with $3.6 \mu \mathrm{mol}$ of $\left[{ }^{13} \mathrm{C}_{20}\right] \beta$-carotene in $2.1 \mathrm{ml}$ groundnut oil, and $4.8 \mu \mathrm{mol}\left[{ }^{2} \mathrm{H}_{4}\right]$ retinol acetate in $0.75 \mathrm{ml}$ groundnut oil. The intrinsically labelled carrots were minimally processed by blanching and homogenisation before storage at $-20^{\circ} \mathrm{C}$. The carrot meals that had no further processing carried out to the carrots will be described as 'raw' in the present study, while those carrots that had been stir-fried, will be described as 'stir-fried'.
Further $10 \mathrm{ml}$ of blood samples were taken at 6, 8, 10 and $13 \mathrm{~h}$ after the meal was given. The subjects then left the HNR unit but returned on each of the following $3 \mathrm{~d}$ for $10 \mathrm{ml}$ of blood samples to be taken at 24, 28, 32, 36, 48, 54 and $72 \mathrm{~h}$ post-dosing. Subjects were allowed to eat and drink normally from $4 \mathrm{~h}$ after consuming the carrots, but they were asked to avoid foods with high carotenoid or vitamin A content (carrots, carrot juices, mangoes, spinach, oily fish and foods cooked in red palm oil) for the $3 \mathrm{~d}$ blood sampling period. Written guidance for this was provided.

\section{Measurement of carotenoid and retinoid concentrations in plasma}

Plasma was separated from the blood by centrifugation, and stored at $-80^{\circ} \mathrm{C}$ until required for analysis. Quantitative determination of (all- $E$ )- $\alpha$-carotene, (all- $E$ )- $\beta$-carotene, $\beta$-cryptoxanthin, retinol palmitate and total retinol was achieved following the method of Thurnham et al. ${ }^{(15)}$, except that the two internal standards, $0.50 \mathrm{nmol}$ trans-ethyl- $\beta$-apo8 -carotenoate and $1.2 \mathrm{nmol}$ all-trans-retinol acetate, were used in place of tocopherol acetate. The final dry extract was reconstituted first in $30 \mu \mathrm{l}$ dichloromethane and then $220 \mu \mathrm{l}$ ACN-MeOH (1:1) were added.

Quantitative HPLC was performed using isocratic separation on a Waters Alliance 2695 Separation Module equipped with a thermostatically controlled $4.6 \mathrm{~mm} \times 100 \mathrm{~mm}$ reverse-phase $\mathrm{C}_{18}$ cartridge column with a $3.5 \mu \mathrm{m}$ particle size and a $10 \mathrm{~nm}$ pore size (Waters Limited). Dual-channel photodiode array detection (Waters Limited) at $450 \mathrm{~nm}$ for carotenoids and at $325 \mathrm{~nm}$ for retinoids was used, and quantification was achieved by comparison with the National Institute of Standards and Technology Standard Reference Material 968c ${ }^{(16)}$.

\section{Preparation of carotenoids and retinol for isotopic analysis}

The overall method is shown schematically in Fig. 1. With reference to this figure, the following six steps are described in detail as follows:

(D) A $2.5 \mathrm{ml}$ sample of plasma was split into three aliquots, and each was deproteinised with ethanol and the lipids were extracted with hexane. The extracts were combined and dried at room temperature under $\mathrm{N}_{2}$ gas.

(E) The dry residue was then redissolved in $600 \mu \mathrm{l}$ of $76: 24 \%$ (v/ v) $\mathrm{MeOH}$-dichloromethane. Semi-preparative chromatography was performed on $200 \mu \mathrm{l}$ aliquots using a Waters 515 pump (Waters UK Ltd) and a Vydac TP201 reversephase column (W. R. Grace \& Co., Deerfield, IL, USA). A Waters 2487 UV-visible detector (Waters UK Ltd) was used to identify fractions absorbing at 325 and $450 \mathrm{~nm}$ for fraction collection. Unesterified retinol was collected separately from the carotenoids and retinyl esters.

(F) After drying under $\mathrm{N}_{2}$, the carotenoid and retinyl ester fraction was redissolved in $2 \mathrm{ml}$ of $2 \%$ ethanolic potassium hydroxide. Saponification was achieved in $25 \mathrm{~min}$ at $45^{\circ} \mathrm{C}$ after which the samples were cooled and $0.5 \mathrm{ml}$ of deionised water were added. The carotenoids and retinol 
were extracted with three washes of hexane $(1 \mathrm{ml})$, which were then combined and dried completely.

(G) The samples were reconstituted in $120 \mu \mathrm{l}$ of $90: 10 \%$ (v/v) $\mathrm{MeOH}$-dichloromethane and separated isocratically on a Vydac 201TP54 column (W. R. Grace \& Co.) using 90:10\% (v/v) MeOH-dichloromethane as the mobile phase. The carotene fraction was then hydrogenated ready for GC-MS analysis as described for the carrot extracts.

(H) The retinol fraction was dried, and then redissolved in $120 \mu \mathrm{l}$ absolute ethanol before further purification using a Waters $\mathrm{C}_{18}$-symmetry cartridge column with gradient elution as follows: ACN-tetrahydrofuran-1\% aqueous ammonium acetate $(50: 20: 30, \mathrm{v} / \mathrm{v} / \mathrm{v}$, in water) was used for $6 \mathrm{~min}$, followed by an $8 \mathrm{~min}$ linear gradient introducing $50 \%$ ACN-tetrahydrofuran-1\% aqueous ammonium chloride (40:44:6, v/v/v). These conditions were held for $5 \mathrm{~min}$ before the second solvent was linearly increased to $100 \%$. These conditions were held for $8 \mathrm{~min}$, and then a $1 \mathrm{~min}$ linear transition to the original solvent was made. The retinol fraction was collected and $2 \mathrm{ml}$ chloroform added. After centrifugation, the aqueous layer was removed and the organic solvents were evaporated under $\mathrm{N}_{2}$.

(I) Retinol was washed with $2 \mathrm{ml}$ ethanol to absorb any remaining water, and then dried before trimethylsilyl diethyl ether was formed using BSTFA (N,O-bis (trimethylsilyl) trifluoroacetamide) in pyridine ${ }^{(17)}$. Trimethylsilyl diethyl ether was dried and reconstituted in $100 \mu \mathrm{l}$ of derivatising agent ready for GC-MS analysis

GC-MS was performed using a 6890 GC series system (Agilent Technologies), with an on-column injection of $1 \mu \mathrm{l}$ of the sample. Chromatographic separation was achieved on a DB1-MS column (J\&W Scientific), with a four-stage temperature programme: $60-200^{\circ} \mathrm{C}$ at $25^{\circ} \mathrm{C} / \mathrm{min}$, followed by $200-235^{\circ} \mathrm{C}$ at $6^{\circ} \mathrm{C} / \mathrm{min}$, then increasing to $330^{\circ} \mathrm{C}$ at $30^{\circ} \mathrm{C} / \mathrm{min}$ and held at $340^{\circ} \mathrm{C}$ for $2.4 \mathrm{~min}$ to elute any remaining materials. An ion source temperature of $150^{\circ} \mathrm{C}$ and a quadrupole temperature of $120^{\circ} \mathrm{C}$ were used. The mass spectrometer was used in low-resolution mode, with signal in the range of $\pm 0.2 \mathrm{~m} / z$ being integrated for each mass measured. Tuning, including a mass scale calibration, was performed before each batch of samples were analysed. The isotopomer ratios were measured in selected ion monitoring mode of the mass cluster $359-371 \mathrm{~m} / \mathrm{z}$ using the peak-fitting method of Bluck \& Coward ${ }^{(12)}$.

It was determined that the $\mathrm{CV}$ on repeated $M+1 / M$ measurements for either hydrogenated $\beta$-carotene or derivatised retinol on the same plasma sample (internal error) was
$<0.5 \%$. The $\mathrm{CV}$ on $M+1 / M$ measurements of different extractions was $1-1.5 \%$

\section{Isotopic analysis of perhydro $\beta$-carotene}

There are expected to be three distinct isotopic species of $\beta$-carotene in the plasma samples: the pre-existing naturally abundant species that labelled randomly with ${ }^{2} \mathrm{H}$ obtained from the carrots, and $\left[{ }^{13} \mathrm{C}_{20}\right] \beta$-carotene given as a reference. After hydrogenation, the measurable peaks in the molecular ion cluster of the first two species are in the range 558$561 \mathrm{~m} / z$, while for the latter, the corresponding signal is at $578-580 \mathrm{~m} / z$. Using the notation described in Table 1 , the mole fractions of all three species can be deduced from mass spectral intensities from

$$
\underline{X}=\left(\underline{\underline{C}}^{T} \underline{\underline{C}}\right)^{-1} \underline{\underline{C}}^{T} \underline{H}
$$

where the matrices

$$
\begin{aligned}
& \underline{\underline{C}}=\left[\begin{array}{cc}
\left(A_{\mathrm{U}}-A_{\mathrm{Y}}\right) R_{559}-\left(B_{\mathrm{U}}-B_{\mathrm{Y}}\right) & A_{\mathrm{U}} R_{559}-B_{\mathrm{U}} \\
\left(B_{\mathrm{U}}-B_{\mathrm{Y}}\right) R_{560}-\left(C_{\mathrm{U}}-C_{\mathrm{Y}}\right) & A_{\mathrm{U}} R_{560}-C_{\mathrm{U}} \\
\left(C_{\mathrm{U}}-C_{\mathrm{Y}}\right) R_{561}-\left(D_{\mathrm{U}}-D_{\mathrm{Y}}\right) & A_{\mathrm{U}} R_{561}-D_{\mathrm{U}} \\
\left(A_{\mathrm{U}}-A_{\mathrm{D}}\right) R_{578} & A_{\mathrm{U}} R_{578}+A_{\mathrm{C}} \\
\left(A_{\mathrm{U}}-A_{\mathrm{D}}\right) R_{579} & A_{\mathrm{U}} R_{579}+B_{\mathrm{C}} \\
\left(A_{\mathrm{U}}-A_{\mathrm{D}}\right) R_{580} & A_{\mathrm{U}} R_{580}+C_{\mathrm{C}}
\end{array}\right], \\
& \underline{H}=\left[\begin{array}{c}
A_{\mathrm{U}} R_{559}-B_{\mathrm{U}} \\
A_{\mathrm{U}} R_{560}-C_{\mathrm{U}} \\
A_{\mathrm{U}} R_{561}-D_{\mathrm{U}} \\
A_{\mathrm{U}} R_{578} \\
A_{\mathrm{U}} R_{579} \\
A_{\mathrm{U}} R_{580}
\end{array}\right]
\end{aligned}
$$

and

$$
\underline{X}=\left[\begin{array}{c}
X_{\mathrm{Y}} \\
X_{\mathrm{C}}
\end{array}\right] \text { (note } X_{\mathrm{U}}=1-X_{\mathrm{Y}}-X_{\mathrm{C}} \text { by defination). }
$$

(see Appendix 2).

The coefficients adopted for the carrot $\beta$-carotene $\left(A_{\mathrm{Y}}, B_{\mathrm{Y}}\right.$, $C_{\mathrm{Y}}, D_{\mathrm{Y}}$ ) were those obtained in the calculation of the degree of intrinsic labelling (see the Results section). Those for the unlabelled (basal) and $\left[{ }^{13} \mathrm{C}_{20}\right] \beta$-carotene were calculated in the same way, but assuming that the element with the major

Table 1. Contributions of each of the three isotopically distinct $\beta$-carotene species in plasma to the

\begin{tabular}{|c|c|c|c|c|c|c|c|c|}
\hline Species & Mole fraction & 558 & 559 & 560 & 561 & 578 & 579 & 580 \\
\hline Unlabelled & $X_{U}=1-X_{Y}-X_{C}$ & $A_{\mathrm{U}}$ & $B_{U}$ & $C_{U}$ & $D_{\cup}$ & 0 & 0 & 0 \\
\hline From carrots & $X_{Y}$ & $A_{Y}$ & $B_{Y}$ & $C_{Y}$ & $D_{Y}$ & 0 & 0 & 0 \\
\hline${ }^{13} \mathrm{C}$-labelled & $X_{\mathrm{C}}$ & 0 & 0 & 0 & 0 & $A_{\mathrm{C}}$ & $B_{\mathrm{C}}$ & $C_{\mathrm{C}}$ \\
\hline
\end{tabular}
overall mass spectrum: the pre-existing naturally abundant species (unlabelled) that labelled randomly with ${ }^{2} \mathrm{H}$ obtained from the carrots (from carrots), and $\left[{ }^{13} \mathrm{C}_{20}\right] \beta$-carotene given as a reference $\left({ }^{13} \mathrm{C}\right.$-labelled $)$ 
deviation from fractional abundance in these compounds was carbon.

\section{Isotopic analysis of trimethylsilyl-retinol}

A similar approach was adopted for trimethylsilyl-retinol, except now there are four isotopically distinct sources to consider: the pre-existing (basal) unlabelled retinol; that due to cleavage of the carrot $\beta$-carotene; some due to cleavage of $\left[{ }^{13} \mathrm{C}_{20}\right] \beta$-carotene $\left(\left[{ }^{13} \mathrm{C}_{10}\right]\right.$ retinol $) ;\left[{ }^{2} \mathrm{H}_{4}\right]$ retinol used as a standard. There are twelve mass numbers that are useful in the spectrum of trimethylsilyl-retinol in the range $358-371 \mathrm{~m} / \mathrm{z}$. The significant contributions of each species are indicated in Table 2. The least-squares solution to the eleven equations in three unknown mole fractions is the solution to:

$$
\left[\begin{array}{crr}
{\left[B_{\mathrm{U}}-B_{\mathrm{Y}}-\left(A_{\mathrm{U}}-A_{\mathrm{Y}}\right) R_{359}\right]} & \left(B_{\mathrm{U}}-A_{\mathrm{U}} R_{359}\right) & \left(B_{\mathrm{U}}-A_{\mathrm{U}} R_{359}\right) \\
{\left[C_{\mathrm{U}}-C_{\mathrm{Y}}-\left(A_{\mathrm{U}}-A_{\mathrm{Y}}\right) R_{360}\right]} & \left(C_{\mathrm{U}}-A_{\mathrm{U}} R_{360}\right) & \left(C_{\mathrm{U}}-A_{\mathrm{U}} R_{360}\right) \\
{\left[D_{\mathrm{U}}-D_{\mathrm{Y}}-\left(A_{\mathrm{U}}-A_{\mathrm{Y}}\right) R_{361}\right]} & \left(D_{\mathrm{U}}-A_{\mathrm{U}} R_{361}\right) & \left(D_{\mathrm{U}}-A_{\mathrm{U}} R_{361}\right) \\
\left(A_{\mathrm{U}}-A_{\mathrm{Y}}\right) R_{362} & A_{\mathrm{U}} R_{362} & \left(A_{\mathrm{D}}+A_{\mathrm{U}} R_{362}\right) \\
\left(A_{\mathrm{U}}-A_{\mathrm{Y}}\right) R_{363} & A_{\mathrm{U}} R_{363} & \left(B_{\mathrm{D}}+A_{\mathrm{U}} R_{363}\right) \\
\left(A_{\mathrm{U}}-A_{\mathrm{Y}}\right) R_{364} & A_{\mathrm{U}} R_{364} & \left(C_{\mathrm{D}}+A_{\mathrm{U}} R_{364}\right) \\
\left(A_{\mathrm{U}}-A_{\mathrm{Y}}\right) R_{365} & A_{\mathrm{U}} R_{365} & \left(D_{\mathrm{D}}+A_{\mathrm{U}} R_{365}\right) \\
\left(A_{\mathrm{U}}-A_{\mathrm{Y}}\right) R_{368} & \left(A_{\mathrm{C}}+A_{\mathrm{U}} R_{368}\right) & A_{\mathrm{U}} R_{368} \\
\left(A_{\mathrm{U}}-A_{\mathrm{Y}}\right) R_{369} & \left(B_{\mathrm{C}}+A_{\mathrm{U}} R_{369}\right) & A_{\mathrm{U}} R_{369} \\
\left(A_{\mathrm{U}}-A_{\mathrm{Y}}\right) R_{370} & \left(C_{\mathrm{C}}+A_{\mathrm{U}} R_{370}\right) & A_{\mathrm{U}} R_{370} \\
\left(A_{\mathrm{U}}-A_{\mathrm{Y}}\right) R_{371} & \left(D_{\mathrm{C}}+A_{\mathrm{U}} R_{371}\right) & A_{\mathrm{U}} R_{371}
\end{array}\right]\left[\begin{array}{l}
X_{\mathrm{Y}} \\
X_{\mathrm{C}} \\
X_{\mathrm{D}}
\end{array}\right]
$$

$$
=\left[\begin{array}{c}
B_{\mathrm{U}}-A_{\mathrm{U}} R_{359} \\
C_{\mathrm{U}}-A_{\mathrm{U}} R_{360} \\
D_{\mathrm{U}}-A_{\mathrm{U}} R_{361} \\
A_{\mathrm{U}} R_{362} \\
A_{\mathrm{U}} R_{573} \\
A_{\mathrm{U}} R_{364} \\
A_{\mathrm{U}} R_{364} \\
A_{\mathrm{U}} R_{365} \\
A_{\mathrm{U}} R_{369} \\
A_{\mathrm{U}} R_{370} \\
A_{\mathrm{U}} R_{371}
\end{array}\right]
$$

In this instance, it is not useful to adopt the same procedure to calculate the coefficients of the mass spectrum as the addition of $\mathrm{Si}$ to the molecule for analysis with large isotopic contributions of its own gives additional complexity, which cannot be resolved. On this basis, the mass spectral coefficients $A, B$, etc. for the labelled species are calculated from the atomic abundances ${ }^{(13)}$, and are given in Table 2 . For the unlabelled (pre-existing) retinal, the coefficient $A_{\mathrm{U}}$ is calculated in the same way, and $B_{\mathrm{U}}, C_{\mathrm{U}}$ and $D_{\mathrm{U}}$ derived from it using the measured basal isotopomer ratios.

\section{Kinetic modelling}

Simple compartmental models were used to interpret the observed kinetics of retinyl palmitate, retinol and $\beta$-carotene. In each of the three cases, the simplest model that accounted for the observed behaviour was employed. Parameter determination was accomplished by minimising the sum of the squared residuals between fitted and experimental data using the non-linear optimisation function in Excel (Microsoft Inc., Redmond, WA, USA).

\section{Retinyl palmitate}

Mean tracer retinyl palmitate kinetics in the period $0 \cdot 25-1 \mathrm{~d}$ after dosing were described by:

$$
R(t)=m_{\mathrm{RE}}\left(1-\exp \left\{-k_{\mathrm{RE}} t\right\}\right),
$$

where $m_{\mathrm{RE}}$ is the total quantity of retinyl palmitate delivered to the sampled pool and $k_{\mathrm{RE}}$ is the fractional rate constant of disappearance. This equation describes the first-order loss of a bolus quantity from a single pool (Fig. 2(a)). This pool was identified as the plasma, and therefore its volume of distribution, $V_{R}$, was estimated by first calculating body surface area from weight and height ${ }^{(18)}$ and then using the prediction equations proposed by Hurley ${ }^{(19)}$. The combined expressions are:

$$
V_{R}(\mathrm{ml})=\left\{\begin{array}{lc}
234.91 \times \text { weight }^{0.5378} \times \text { height }^{0.3964} & \text { for men } \\
212.32 \times \text { weight }^{0.5378} \times \text { height }^{0.3964} & \text { for women }
\end{array}\right.
$$

\section{Retinol}

For tracer retinal, a dual exponential function was needed to describe the observed kinetics:

$$
R(t)=\left\{\begin{array}{cc}
0 & t<\tau \\
m_{R}\left(\exp \left\{-g_{R 1}(t-\tau)\right\}-\exp \left\{-g_{R 2}(t-\tau)\right\}\right) & t \geq \tau
\end{array}\right.
$$

where $m_{R}, g_{R 1}, g_{R 2}$ and $\tau$ are constants, the latter representing a delay between dosing and the appearance of the dose in the plasma. This expression is characteristic of a pool fed by a pool to which the dose has been delivered, and with a route of irreversible loss (Fig. 2(b)). 
Table 2. Contributions of each of the four isotopically distinct retinol species in plasma to the overall mass spectrum: the pre-existing (basal) unlabelled retinol (unlabelled); that due to cleavage of the carrot $\beta$-carotene (from carrot $\beta$-carotene); some due to cleavage of $\left[{ }^{13} \mathrm{C}_{20}\right] \beta$-carotene, namely $\left[{ }^{13} \mathrm{C}_{10}\right]$ retinol (from $\left[{ }^{13} \mathrm{C}_{20}\right] \beta$-carotene) and $\left[{ }^{2} \mathrm{H}_{4}\right]$ retinol used as a standard (from $\left[{ }^{2} \mathrm{H}_{4}\right]$ retinol acetate)

\begin{tabular}{lllll}
\hline Species & Unlabelled & From carrot $\beta$-carotene & From $\left[{ }^{13} \mathrm{C}_{20}\right] \beta$-carotene & From $\left[{ }^{2} \mathrm{H}_{4}\right]$ retinol acetate \\
\hline Mole fraction & $X_{\mathrm{U}}=1-X_{\mathrm{Y}}-X_{\mathrm{C}}-X_{\mathrm{D}}$ & $X_{\mathrm{Y}}$ & $X_{\mathrm{C}}$ & $X_{\mathrm{D}}$ \\
358 & $A_{\mathrm{U}}=0.707553$ & $A_{\mathrm{Y}}=0.590528$ & & \\
359 & $B_{\mathrm{Y}}$ & $B_{\mathrm{Y}}=0.293254$ & & \\
360 & $C_{\mathrm{Y}}=0.091837$ & & \\
361 & $D_{\mathrm{Y}}=0.020522$ & & $A_{\mathrm{D}}=0.707978$ \\
362 & & & $B_{\mathrm{D}}=0.222735$ \\
363 & $\mathrm{C}_{U}$ & & & \\
364 & & $C_{\mathrm{D}}=0.058264$ \\
365 & & $A_{\mathrm{C}}=0.791107$ & \\
& & $B_{\mathrm{C}}=0.1160565$ & \\
& & $C_{\mathrm{C}}=0.042746$ & \\
& & $D_{\mathrm{C}}=0.005159$ & \\
\hline
\end{tabular}

\section{$\beta$-Carotene}

The time courses of plasma tracer $\beta$-carotene, obtained by multiplying the total plasma concentration from HPLC by the mole fraction obtained from GC-MS, are described by the single exponential function:

$$
\beta(t)=m_{\beta}\left(1-\exp \left\{-k_{\beta} t\right\}\right)
$$

where $m_{\beta}$ and $k_{\beta}$ are constants. This expression is typical of a compartment with a constant flux input, and first-order irreversible loss (Fig. 2(c)). When performing the optimisation for this model, the data obtained in the first $12 \mathrm{~h}$ after dosing were not included, since this is dominated by the transient chylomicron transport of newly absorbed $\beta$-carotene to the liver.

\section{Results}

\section{Carotenoid content of the intrinsically labelled carrots}

Analysis of the raw carrots, after minimal processing of blanching and homogenisation, indicated that each $100 \mathrm{~g}$ (wet weight) contained 3.45 (SD 0.44) $\mathrm{mg}(6.4$ (SD 0.5) $\mu \mathrm{mol}$ ) $\alpha$-carotene and 3.79 (SD 0.44$) \mathrm{mg} \quad(7.1 \quad$ (SD 0.8$) \mu \mathrm{mol}$ ) $\beta$-carotene, approximately the same levels $(3 \mathrm{mg} / 100 \mathrm{~g}$ and $6 \mathrm{mg} / 100 \mathrm{~g}$, respectively) are reported elsewhere for young carrots $^{(20)}$. The fractional abundance of ${ }^{2} \mathrm{H}$ in $\beta$-carotene obtained by combining five individual estimates was 0.636 (sD 0.036 ) atom $\%$, representing an enrichment of $0.621 \%$ above natural abundance.

This labelling pattern produces a theoretical mass spectrum with relative abundances of $0.4461(\mathrm{SD} 0.0041$ ) at $558 \mathrm{~m} / z$, $0 \cdot 3616(\mathrm{sD} 0 \cdot 0008)$ at $559 \mathrm{~m} / z, 0 \cdot 1450(\mathrm{SD} 0 \cdot 0020)$ at $560 \mathrm{~m} / z$ and $0.0384(\mathrm{SD} 0.0010)$ at $561 \mathrm{~m} / z$ (isotopomer ratios $R_{559}=81 \cdot 1$ (sD 0.9$) \%, R_{560}=32.5(\mathrm{sD} 0.7) \%$ and $R_{561}=8.6(\mathrm{sD} 0.3) \%$ ), which was used in the speciation of plasma $\beta$-carotene.

\section{Volunteer characteristics}

Volunteer characteristics are given in Table 3. Of the subjects, one (D) did not complete one of the days' protocol and was therefore excluded from the analysis. Plasma volume from weight and height considerations was estimated to be 2.9 (SD 0.2) litres. The meals were given in randomised order. No difference in vitamin A status, judged by pre-meal plasma concentrations of $\beta$-carotene or retinol, was noted.

\section{Plasma carotenoid and retinoid concentrations after meal ingestion}

There was no detectable increase in plasma $\alpha$ - or $\beta$-carotene concentration due to either meal protocol. Although plasma retinol was similarly unperturbed, retinyl palmitate showed a significant increase after both meals. Generally speaking, the peak value of retinyl palmitate had already occurred before $6 \mathrm{~h}$ after dosing, when the increments were 826 (SD 145) $\mathrm{nmol} / \mathrm{l}(P<0.01)$ and $888(\mathrm{SD} 243) \mathrm{nmol} / \mathrm{l}(P \sim 0.07)$ for the raw and stir-fried meals, respectively.

The averaged values obtained from the four subjects were fitted to an exponential (equation 1) in the period $0 \cdot 25-1 \mathrm{~d}$, giving $k_{\mathrm{RE}}$ equal to $2 \cdot 8$ (SD 0.4 ) per $\mathrm{d}$ after the raw carrot meal and 3.2 (SD 0.7 ) per $d$ after the stir-fry. When extrapolated back to zero time, the intercepts of the curves were $1 \cdot 3$ and $1 \cdot 1 \mu \mathrm{mol} / 1$, which when combined with the estimates of plasma volume correspond to 3.0 and $3.2 \mu \mathrm{mol}$ for the raw meal and the stir-fried meal, respectively.

\section{Plasma retinol kinetics}

Typical retinol kinetics obtained from the stable isotope data are shown in Fig. 3. The values obtained for the macroparameters $\tau, g_{R 1}$ and $g_{R 2}$ are given in Table 4. Since there are no significant differences in these three parameters between the retinol species, each test was remodelled assuming common values as this gives additional strength to the analysis. Using this approach, the self-consistent parameters for the raw carrot meal were found to be $\tau=0.19$ (SD 0.01) d, $g_{R 1}=0.77$ (SD 0.07) per $\mathrm{d}, g_{R 2}=10.8$ (SD 0.3) per $\mathrm{d}$, $m_{R}\left({ }^{2} \mathrm{H}_{4}\right)=0.193 \quad(\mathrm{SD} \quad 0.012) \mu \mathrm{mol} / 1$ and $m_{R}\left({ }^{13} \mathrm{C}_{10}\right)=0.065$ (SD 0.017$) \mu \mathrm{mol} / 1$, while for the stir-fried meal, the values $\tau=0.22(\mathrm{SD} 0.02) \mathrm{d}, g_{R 1}=0.81$ (SD 0.09) per d, $g_{R 2}=10.3$ (sD 1.1) per d, $m_{R}\left({ }^{2} \mathrm{H}_{4}\right)=0.206 \quad(\mathrm{sD} 0.020) \mu \mathrm{mol} / 1$ and $m_{R}\left({ }^{13} \mathrm{C}_{10}\right)=0.055(\mathrm{sD} 0 \cdot 017) \mu \mathrm{mol} / \mathrm{l}$ were found. 
(a)

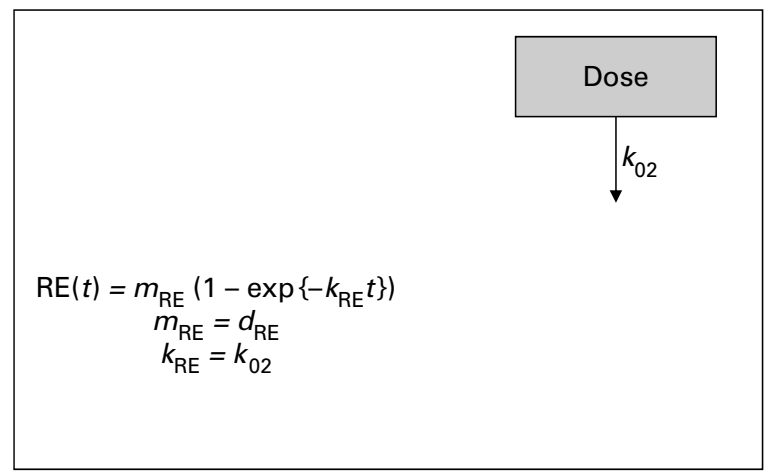

(b)

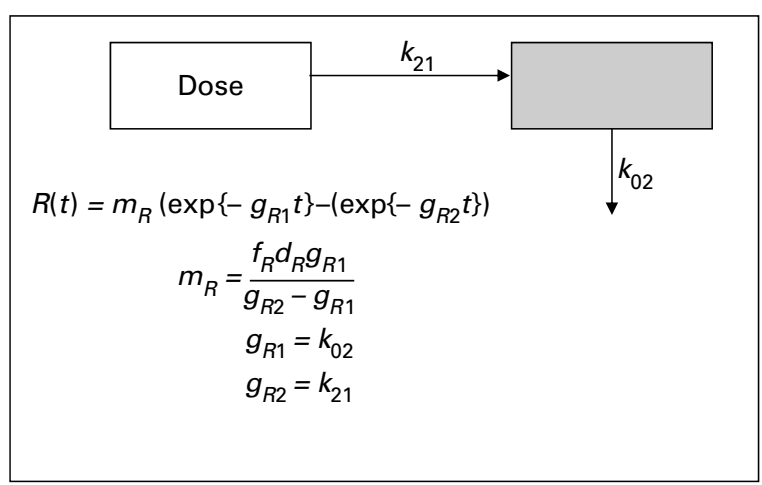

(c)

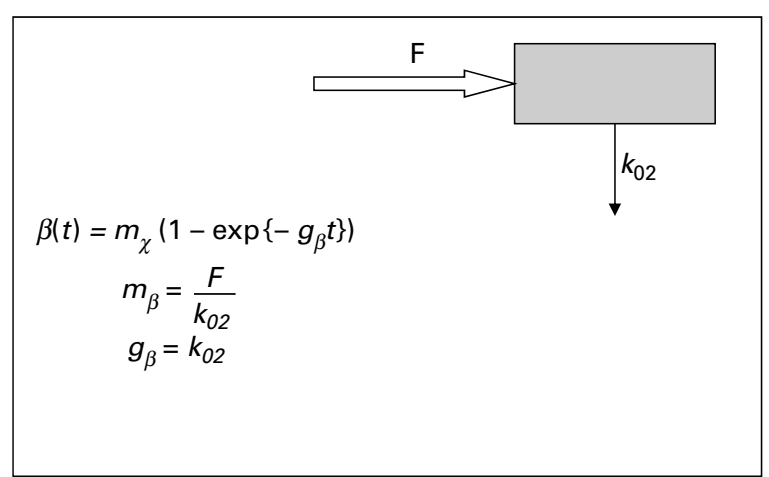

Fig. 2. Parsimonious models used: (a) model of retinyl ester kinetics, (b) model of retinol tracer kinetics and (c) model of $\beta$-carotene tracer kinetics. In each case, $\square$ indicates the sampled compartment. The equations relate the fundamental fractional rate constants in the model to the experimentally determined parameters. retinol equivalent

\section{Plasma carotenoid kinetics}

A typical time course of plasma $\beta$-carotene is shown in Fig. 4. The early stages $(t<0.5 \mathrm{~d})$ represent $\beta$-carotene being carried to the liver in the chylomicron fraction of the lipid. The lifetime of chylomicrons is relatively short, and the profile of the curve in this early phase is governed both by the length of the period of $\beta$-carotene absorption (which in turn is a function of gastric-emptying rate and rate of transport through the enterocytes) and the rate of the hepatic breakdown of chylomicrons. The shape of the curve after the initial transient event approximates to an exponential rise to a steady plateau, typical of the kinetics of steady release into a single compartment with a small fractional rate of loss. Adopting this model and fitting using equation 4 in terms of $m_{\beta}$ and $k_{\beta}$, a similar observation was made to that for retinol inasmuch as the fractional rate constant was independent of isotopic species, and therefore final analysis was performed using a common value of $k_{\beta}$ for the two species. Its value was found to be 4.3 (SD 1.7) per $\mathrm{d}$ for the raw carrot meal and $4 \cdot 1$ (SD 0.4 ) per $\mathrm{d}$ for the stir-fried meal. For $\left[{ }^{13} \mathrm{C}_{20}\right] \beta$-carotene, $m_{\beta}$ was found to be 0.051 (SD 0.007) $\mu \mathrm{mol} / \mathrm{l}$ for the raw carrot meal and $0.031 \quad$ SD 0.011$) \mu \mathrm{mol} / 1$ for the stir-fried meal $(P<0.005)$, while for the carrot-derived material $m_{\beta}$ was found to be 0.011 (SD 0.004$) \mu \mathrm{mol} / \mathrm{l}$ and 0.035 (SD $0.006) \mu \mathrm{mol} / \mathrm{l}$ for the raw and stir-fried meals, respectively $(P=0 \cdot 03)$.

Of more significance is the product of the two parameters, $m_{\beta} k_{\beta}$, since this represents the constant flux entering the sampled compartment. For $\left[{ }^{13} \mathrm{C}_{20}\right] \beta$-carotene, it was found to be $0.24(\mathrm{SD} 0 \cdot 12) \mu \mathrm{mol} / 1$ per $\mathrm{d}$ for the raw carrot meal and 0.12 (SD 0.03$) \mu \mathrm{mol} / 1$ per $\mathrm{d}$ for the stir-fried meal (not significantly different by the paired $t$ test), while for the carrotderived material, it was found to be 0.03 (SD 0.01) $\mu \mathrm{mol} / 1$ per $\mathrm{d}$ and $0 \cdot 14(\mathrm{SD} 0 \cdot 01) \mu \mathrm{mol} / \mathrm{l}$ per $\mathrm{d}(P=0 \cdot 001)$ for the raw and stir-fried meals, respectively. Total $\beta$-carotene turnover can be derived by first multiplying the plasma volume by the concentration to give 1.2 (SD 0.2) $\mu \mathrm{mol}$, which is in good agreement with Novotny ${ }^{(21)}$, and then combining this with $k_{\beta}$ to obtain an estimate of turnover of $5 \cdot 1$ (SD 1.8$) \mu \mathrm{mol} / \mathrm{d}$.

\section{Discussion}

A comprehensive model of vitamin A metabolism has been given by Novotny ${ }^{(21)}$ and is reproduced in Fig. 5. From this model, the qualitative aspects of the time profiles of plasma $\beta$-carotene and retinol following ingestion of a carotenoidrich meal can be described (Fig. 6). Roughly $20 \%$ of the ingested $\beta$-carotene is cleaved to retinol in the enterocytes, and both this and the parent compound appear transiently in the chylomicron lipids as they are transported to the liver The liver acts as a buffer for both $\beta$-carotene and retinol, releasing both to the bloodstream in lipid fractions for transport to the sites of action and subsequent irreversible loss. The approximate half-life in plasma of the buffered $\beta$-carotene is predicted to be just over $3 \mathrm{~d}$, with that of retinol being slightly lower at $2 \cdot 8 \mathrm{~d}$.

While this model qualitatively describes the kinetics of $\beta$-carotene and retinol that we observed in the present study, the model is too complicated to be tested by our measurements, and therefore we were unable to use it to quantitatively investigate our experimental data. Instead, we have used simple one- and two-compartment models to describe plasma $\beta$-carotene and retinal, respectively. Our models are not based on detailed physiological considerations, but instead are selected on a principle of parsimony so that they may be described with the minimum experimental data.

Unfortunately, an ambiguity is likely to arise when analysing data in terms of these models in the absence of other information. This is illustrated by considering the solution for a mammillary model, which is known to be:

$$
y=\frac{m g_{1}}{\left(g_{2}-g_{1}\right)}\left(\exp \left\{-g_{1} t\right\}-\exp \left\{-g_{2} t\right\}\right)
$$


where $g_{1}$ is the fractional rate constant of the input to, and $g_{2}$ that of the output from, the sampled compartment. However, simple rearrangement gives

$$
\begin{aligned}
y & =\frac{\left(m \frac{g_{1}}{g_{2}}\right) g_{2}}{\left(g_{1}-g_{2}\right)}\left(\exp \left\{-g_{2} t\right\}-\exp \left\{-g_{1} t\right\}\right) \\
& =\frac{m^{\prime} g_{2}}{\left(g_{1}-g_{2}\right)}\left(\exp \left\{-g_{2} t\right\}-\exp \left\{-g_{1} t\right\}\right) .
\end{aligned}
$$

In other words, in the absence of further evidence, it is not possible to unambiguously assign the rate constants to influx or efflux. In the cases encountered in the present study, any decision must be based on how well the parameter $m$ or $m^{\prime}$ can be reconciled with the total flux of material through the pool.

The sizes of the doses administered in the present study were designed to mimic habitual daily intake. A total of just over $10 \mu \mathrm{mol} \beta$-carotene were ingested with the meal, which is in the range of typical daily intakes of $5-12 \mu \mathrm{mol}^{(22)}$. In contrast, other stable isotope studies of vitamin A metabolism have used doses of pharmacological size $^{(21,23)}$. The doses employed in the present study can be regarded as tracer in nature, since there was no observed perturbation of either the plasma $\beta$-carotene or retinol pools.

Modelling the kinetics of vitamin A metabolism is made difficult by hepatic take-up and re-release of both retinol itself and the provitamins such as $\beta$-carotene. When $\beta$-carotene is ingested, only a fraction is absorbed and transported to the bloodstream. During this process, some are converted to retinyl palmitate, and another fraction is irreversibly lost. Chylomicron $\beta$-carotene, therefore, does not represent the total vitamin A, which is derived from the dietary provitamin. Additionally, the rapid nature of its metabolism requires frequent blood sampling for its measurement. Lipoprotein $\beta$-carotene, on the other hand, is derived from a large buffer stored in the liver, and therefore an ingested bolus enjoys a prolonged re-release into the bloodstream. The kinetics are much slower, but there would have been more material lost by conversion to retinol in the liver. Conversely, chylomicron retinol reflects the fraction of dietary $\beta$-carotene, which is absorbed and converted in the enterocytes, while the other plasma retinol (bound to protein) is again released from the buffered hepatic stores.

In the present study, we chose to add extrinsically labelled material to our intrinsically labelled meal to act as reference standards. Our hypothesis is that a labelled $\beta$-carotene could be used to determine the bioavailability with respect to the free compound of that material in a food matrix, while labelled retinol would allow the partitioning of the provitamin to retinol to be investigated. As discussed earlier, the investigation of total vitamin A kinetics requires frequent blood sampling in the period immediately after dose administration followed by a period of relatively infrequent samples over a longer time period. However, in order to reduce the burden on our volunteers, we chose not to study the acute phase closely, but instead to focus on the longer-term kinetics, 


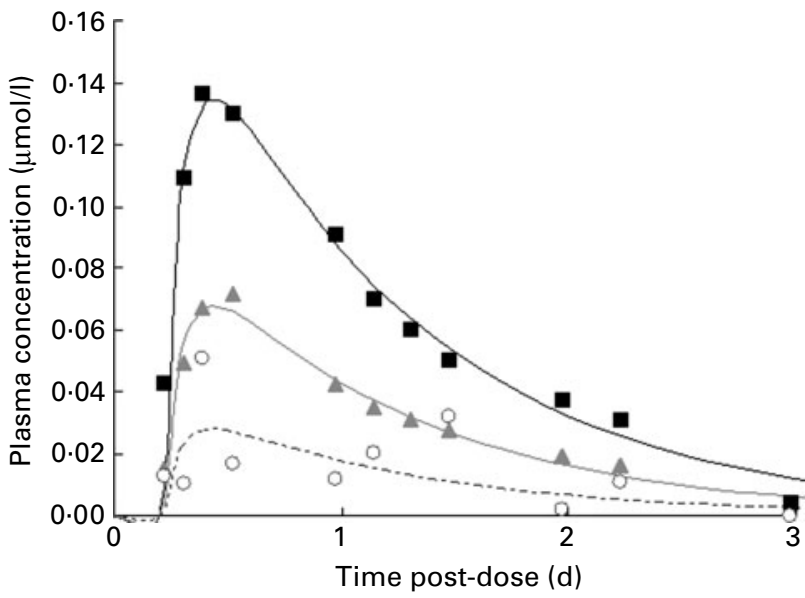

Fig. 3. Typical plasma retinol concentration $v$. time profiles for the five subjects over a $4 \mathrm{~d}$ study period, after consumption of a single bolus meal of $100 \mathrm{~g}$ of the intrinsically labelled carrots (either raw or stir-fried in $10.5 \mathrm{ml}$ groundnut oil), with $4.8 \mu \mathrm{mol}\left[{ }^{2} \mathrm{H}_{4}\right]$ retinol acetate and $3.6 \mu \mathrm{mol}\left[{ }^{13} \mathrm{C}_{20}\right] \beta$-carotene in groundnut oil. Plasma $\left[{ }^{2} \mathrm{H}_{4}\right]$ retinol $(\boldsymbol{\square})$ and $\left[{ }^{13} \mathrm{C}_{10}\right]$ retinol $(\Delta)$ are derived from the $\left[{ }^{2} \mathrm{H}_{4}\right]$ retinol acetate and $\left[{ }^{13} \mathrm{C}_{20}\right] \beta$-carotene doses, respectively. $\mathrm{O}$, Carrot retinol.

since these are more useful in assessing the amount of useful retinol ultimately derived from the meal.

Because of the nature of the way it was given, it was expected that the dose of retinol acetate would be completely and rapidly absorbed. The acute chylomicron response observed is not inconsistent with this assumption. In the kinetic curves, a maximum concentration is achieved very quickly (in $<6 \mathrm{~h}$ ), followed by a slower decay back to basal levels over the next $24 \mathrm{~h}$ or so. This behaviour can be predicted by a simple model comprising a compartment with either rapid input and relatively slow output, or with slow input and relatively rapid output. We have chosen the former, and furthermore made the assumption that the rapid nature of the input is such that it can be approximated to a bolus. This reduces the model to that shown in Fig. 2(a), and allows the identification of the experimental parameter $k_{R}$ with the fractional rate of clearance of retinyl palmitate from plasma. This interpretation is supported by its identification of the parameter $m_{R}$ with the total amount of substrate to pass through the pool, assumed to be the plasma. The product of estimated plasma volume and $m_{R}$ amounts to $78 \%$

Table 4. Retinol kinetics obtained for each subject (A-E) after consumption of either the raw or stir-fried (SF) meals

\begin{tabular}{|c|c|c|c|c|c|c|}
\hline & \multicolumn{3}{|c|}{$\left[{ }^{2} \mathrm{H}_{4}\right]$ Retinol } & \multicolumn{3}{|c|}{$\left[{ }^{13} \mathrm{C}_{10}\right]$ Retinol } \\
\hline & $\begin{array}{l}\tau \\
\text { (d) }\end{array}$ & $\underset{(\text { per d) }}{g_{R 1}}$ & $\begin{array}{c}g_{R 2} \\
\text { (per d) }\end{array}$ & $\begin{array}{l}\tau \\
\text { (d) }\end{array}$ & $\underset{\text { (per d) }}{g_{R 1}}$ & $\underset{(\text { per d) }}{g_{R 2}}$ \\
\hline A Raw & 0.22 & 0.93 & 11.38 & 0.22 & 0.94 & 10.03 \\
\hline A SF & 0.20 & 0.97 & 11.23 & 0.21 & 1.04 & 9.38 \\
\hline B Raw & 0.16 & 0.64 & $11 \cdot 13$ & 0.16 & 0.59 & 9.38 \\
\hline B SF & 0.18 & 0.70 & $10 \cdot 15$ & 0.21 & $2 \cdot 19$ & 4.36 \\
\hline C Raw & 0.20 & 0.83 & 11.63 & 0.25 & 0.45 & $9 \cdot 36$ \\
\hline C SF & 0.26 & 0.89 & 7.53 & 0.34 & 1.08 & 10.00 \\
\hline E Raw & 0.20 & 0.97 & $11 \cdot 12$ & 0.29 & 0.59 & $10 \cdot 87$ \\
\hline E SF & 0.21 & 0.64 & 9.04 & 0.21 & 0.02 & 12.06 \\
\hline
\end{tabular}

of the dose of retinyl palmitate administered for the raw carrots and $70 \%$ for the stir-fried ones, which is consistent with our hypothesis that the method of administration of retinol acetate would render it highly bioavailable.

Our choice of rapid uptake and relatively slow elimination of retinyl ester is discordant with the interpretation of Novotny et $a l^{(21)}$. In their interpretation with slow uptake and rapid elimination, the maximum instantaneous quantity of retinyl ester in the chylomicron pool given by:

$$
\frac{D k_{1}}{k_{2}-k_{1}}\left[\left(\frac{k_{1}}{k_{2}}\right)^{-k_{1} /\left(k_{1}-k_{2}\right)}-\left(\frac{k_{1}}{k_{2}}\right)^{-k_{2} /\left(k_{1}-k_{2}\right)}\right]
$$

is about $1.2 \%$ of the dose given, which is incompatible with the observed maximum concentration. Transposing the assignment of the input and output rate constants given by Novotny predicts a maximum instantaneous quantity in the pool of $93 \%$ of the dose approximately $0.75 \mathrm{~h}$ after dose administration, which is in good agreement with the present observations. We therefore identify our estimated value for $k_{\mathrm{RE}}$ with that (erroneously) associated with retinyl ester absorption in the Novotny model.

Further evidence for the fast uptake/slow elimination model that we propose is the close agreement between our value for $k_{2}$ and its associated half-time of about $0.25 \mathrm{~d}$ and that found for chylomicron clearance itself ${ }^{(24)}$. A lower limit can be placed on $k_{\text {in }}$ (by virtue of the maximum concentration must occur before $0 \cdot 25 \mathrm{~d}$ ) of $5 \cdot 2 / \mathrm{d}$, which is indicative of the ready bioavailability of retinol acetate in palm oil.

Protein-bound retinol derived from chylomicron-bound retinyl esters begins to appear in the plasma approximately $6 \mathrm{~h}$ after meal ingestion, after which it can be described by a two-compartment model. Again, there is a potential ambiguity with defining which of the two fractional rate

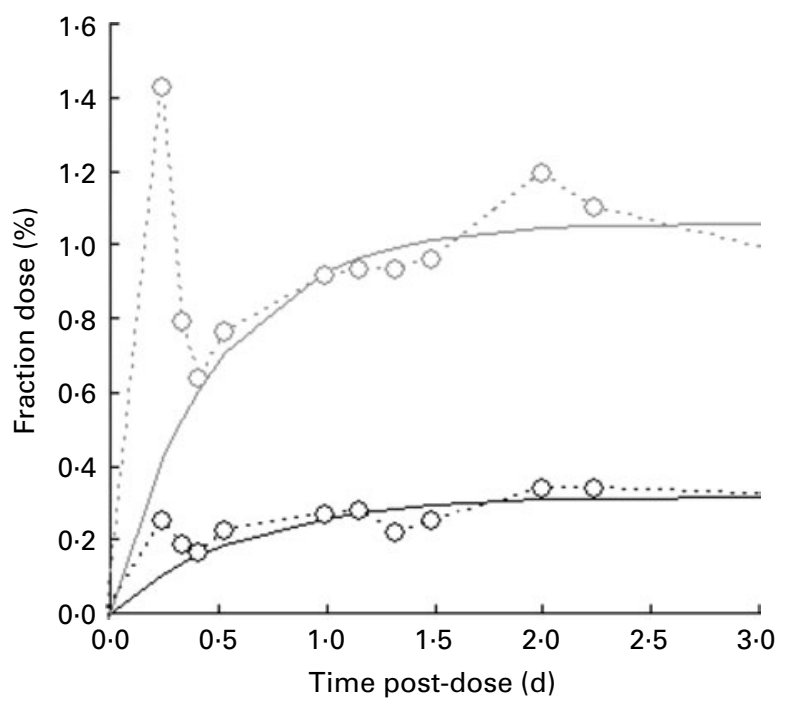

Fig. 4. Typical time course of plasma $\beta$-carotene, fraction of dose $v$. time profiles for the five subjects over a $4 \mathrm{~d}$ study period, after consumption of a single bolus meal of $100 \mathrm{~g}$ of the intrinsically labelled carrots (O; either raw or stir-fried in $10.5 \mathrm{ml}$ groundnut oil), with $4.8 \mu \mathrm{mol}\left[{ }^{2} \mathrm{H}_{4}\right]$ retinol acetate and $3.6 \mu \mathrm{mol}\left[{ }^{13} \mathrm{C}_{20}\right] \beta$-carotene in groundnut oil. Plasma C20 (O) is derived from the $\left[{ }^{13} \mathrm{C}_{20}\right] \beta$-carotene dose. 


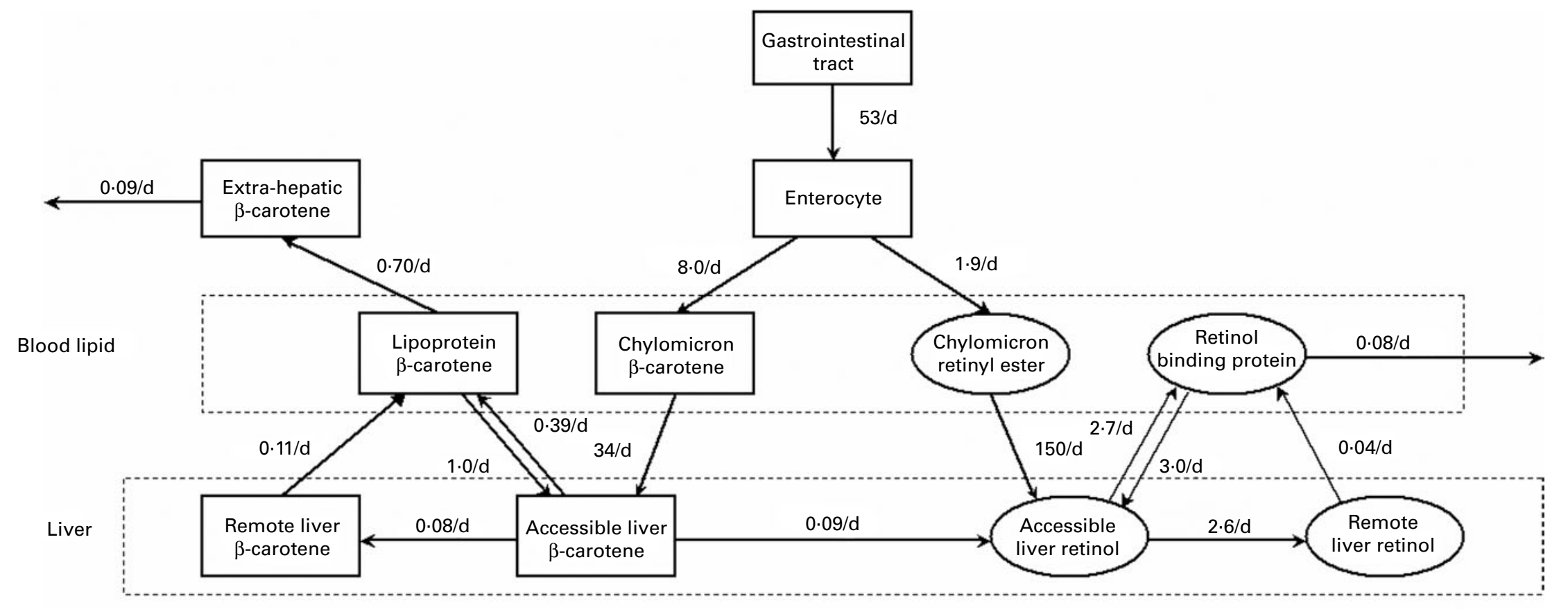

Fig. 5. Compartmental model of $\beta$-carotene metabolism in human subjects (adapted from Novotny et al. ${ }^{(21)}$ ). In this diagram, $\beta$-carotene is designated by rectangular boxes and retinol by ovals. The values above the arrows are fractional rate constants for inter-compartmental transfer deduced from the flows and masses given in the original. 
Chylomicron $\beta$-carotene
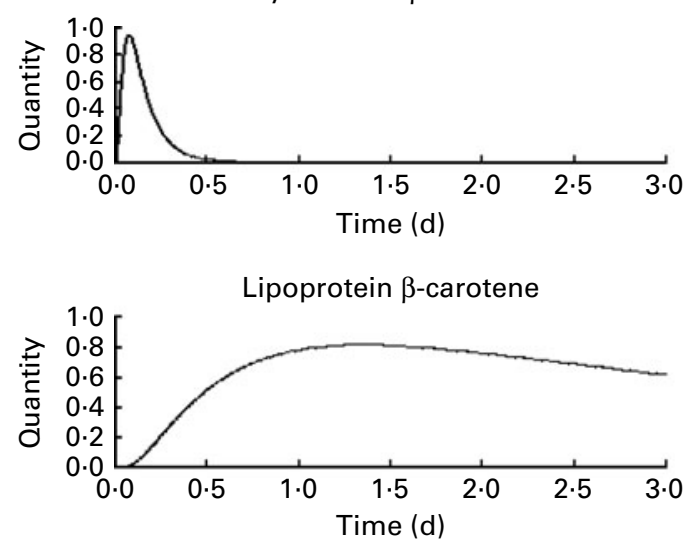

Chylomicron retinyl ester
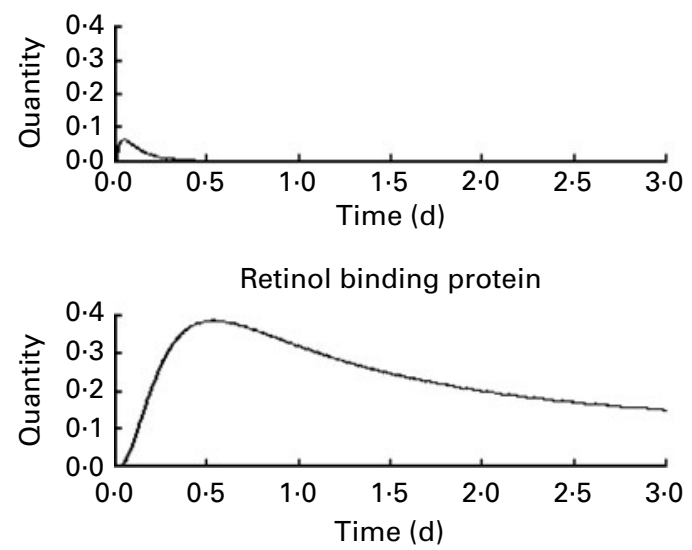

Total plasma $\beta$-carotene

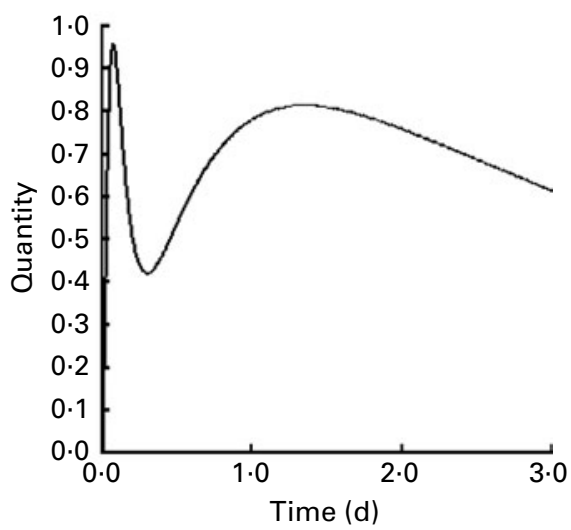

Total plasma retinol

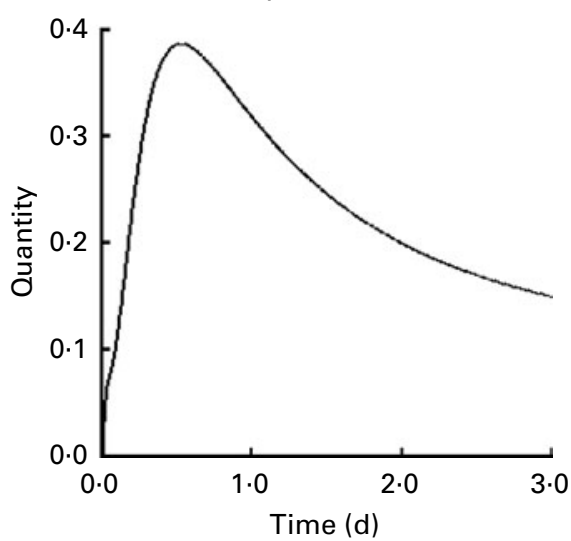

Fig. 6. Qualitative aspects of the time profiles of plasma $\beta$-carotene and retinol following ingestion of a carotenoid-rich meal, containing $7 \mu \mathrm{mol} \beta$-carotene, according to the model given by Novotny et al. ${ }^{(21)}$.

constants obtained represents plasma clearance, which can be resolved by the plasma concentration. Assigning the rate constants $g_{1}=k_{02}$ and $g_{2}=k_{21}$, and assuming that the retinal-binding protein is confined to plasma (the minimum possible distribution volume), then the total quantity of $\left[{ }^{2} \mathrm{H}_{4}\right]-$ retinol to pass through this pool after the raw carrot meal is $\left(f_{R}^{H} d_{R}^{H}\right) \approx 0.5 \mu \mathrm{mol}$ ( $10 \%$ of the dose), whereas if the assignment is reversed, it is found to be about $160 \%$ of the dose given. On this basis, the kinetics of hepatic release of protein-bound retinol into plasma is relatively fast $\left(k_{21} \approx 10\right.$ per $\mathrm{d})$, with relatively slow irreversible loss $\left(k_{21} \approx 0.8\right.$ per $\left.\mathrm{d}\right)$.

The fraction of the $\left[{ }^{2} \mathrm{H}_{4}\right]$ retinyl ester dose, which is re-released into the plasma bound to protein, was not significantly different between the meals (10.7 (SD 0.5)\% after the raw carrot meal and 11.4 (SD 1.7) \% after the stir-fried meal). Combining this with the results from the retinyl ester kinetics indicates that about $15 \%$ of the 'absorbed' retinol is bioavailable in the short-term. Presumably the remaining $85 \%$ are sequestered in deeper hepatic stores.

The amount of dietary free $\beta$-carotene equivalent to $1 \mu \mathrm{mol}$ of dietary retinyl ester is calculated by:

$$
\text { Free retinol equivalent }=\frac{\operatorname{dose}\left({ }^{13} \mathrm{C}_{10}\right)}{\operatorname{dose}\left({ }^{2} \mathrm{H}_{4}\right)} \frac{m_{R}\left({ }^{2} \mathrm{H}_{4}\right)}{m_{R}\left({ }^{13} \mathrm{C}_{10}\right)},
$$

and found to be 2.9 (SD 0.8 ) for the raw carrot meal and 3.7 (SD $1 \cdot 0)$ for the stir-fried meal (paired $t$ test, $P=0 \cdot 04$ ). These values are of the same order as the generally accepted retinol equivalent (RE; $3.2 \mu \mathrm{mol} \beta$-carotene/ $\mu \mathrm{mol}$ retinol, equivalent to $6 \mu \mathrm{g} / \mu \mathrm{g}$ ), much higher than would be expected if $\beta$-carotene cleaved symmetrically and both halves of the molecule were utilised, which would give a value of $0.5 \mu \mathrm{mol} / \mu \mathrm{mol}$.

The difference in $\left[{ }^{13} \mathrm{C}_{10}\right] \beta$-carotene behaviour between the meals is further illustrated by comparing $m_{\beta}$. The amount of the tracer material found in plasma lipoprotein from the stir-fried meal was 56 (SD 13) \% of that from the raw carrot meal. It therefore appears that the reduced free retinol equivalent from the stir-fried meal is due to poorer absorption of the free $\beta$-carotene, rather than differences in post-absorptive processing.

The relative bioavailability of $\beta$-carotene from the carrots and the free compound is calculated via

$$
\frac{\operatorname{dose}\left({ }^{13} \mathrm{C}_{10}\right)}{\operatorname{dose}(\text { carrot })} \frac{m_{\beta} \text { (carrot) }}{m_{\beta}\left({ }^{13} \mathrm{C}_{10}\right)},
$$

which was found to be 11 (SD 5)\% for the raw carrot meal and 74 (SD 19) $\%$ for the stir-fried meal $(P=0 \cdot 01)$. Finally, the RE of carrot-derived $\beta$-carotene can be calculated by combining the 
observation of retinol and $\beta$-carotene:

$$
\mathrm{RE}=\frac{\mathrm{dose}(\text { carrot })}{\operatorname{dose}\left({ }^{2} \mathrm{H}_{4}\right)} \frac{m_{R}\left({ }^{2} \mathrm{H}_{4}\right)}{m_{R}\left({ }^{13} \mathrm{C}_{10}\right)} \frac{m_{\beta}\left({ }^{13} \mathrm{C}_{10}\right)}{m_{\beta} \text { (carrot) }},
$$

which is found to be 41 (SD 16) $\mu \mathrm{mol} / \mu \mathrm{mol}$ for the raw carrots, but only $6 \cdot 2$ (SD $2 \cdot 5) \mu \mathrm{mol} / \mu \mathrm{mol}$ when the carrots are stir-fried. Stir-frying therefore increases carotenoid bioavailability from the carrot more than six-fold.

The RE of $\beta$-carotene in food has been the subject of investigations over many years. Initial estimates of $6 \mu \mathrm{g}$ carotene/ $\mu \mathrm{g}$ retinol $(\equiv 3.2 \mu \mathrm{mol} / \mu \mathrm{mol})^{(25-27)}$ were derived from the work of Hume $\& \mathrm{Krebs}^{(28)}$. This was based on the assumptions that retinol was derived from absorbed $\beta$-carotene on an equimolar basis, and that, on average, dietary $\beta$-carotene was about one-third as bioavailable as retinol. Subsequently, this value has been revised to $12 \mu \mathrm{g} / \mu \mathrm{g}(\equiv 6.4 \mu \mathrm{mol} / \mu \mathrm{mol})$ by the US Institute of Medicine ${ }^{(29)}$. However, it is naive to imagine that a single RE is universally applicable to all foods not only does the food itself matter but factors such as cooking and other processing methods have been shown to have a profound effect ${ }^{(30-35)}$. Recognition that these and other factors determine carotenoid bioavailability from foods has led to the introduction of the SLAMENGHI mnemonic ${ }^{(36)}$.

The RE values obtained in the present study $(77 \mu \mathrm{g} / \mu \mathrm{g}$ for raw carrots and $11.6 \mu \mathrm{g} / \mu \mathrm{g}$ when stir-fried) fall each side of the value of $14.8 \mu \mathrm{g} / \mu \mathrm{g}$ reported for the steamed vegetable ${ }^{(35)}$, and may be compared with that of $13 \mu \mathrm{g} / \mu \mathrm{g}$ for sautéed sweet potato, $10 \mu \mathrm{g} / \mu \mathrm{g}$ for steamed sautéed Indian spinach ${ }^{(37)}$ and $21 \mu \mathrm{g} / \mu \mathrm{g}^{(35)}$ for steamed spinach. Clearly, cooking generally increases bioavailability, and from this limited evidence, the addition of oil or fat in frying is the optimal method of those investigated so far. However, the present study has merely demonstrated that two factors could have contributed to the difference in the yield of retinol: either the frying process or the use of more oil $(10.5 \mathrm{ml})$ for stir-frying the carrots is effective in increasing bioavailability. It was the intention of the present study to compare raw carrot with stir-fried as might be performed in meal preparation in a typical family kitchen. The quantity of oil we chose was sufficient to cook the carrots without leaving appreciable amounts in the pan when the carrots were served. Investigations into the optimal quantity of oil are required in future. In summary, when formulating strategies for the use of vegetables as a sustainable and effective way of combating VAD, cooking methods must be considered.

\section{Acknowledgements}

We would like to acknowledge the Medical Research Council for funding the present study. We would like to thank Kerry Jones, Antony Wright, Neal Matthews and Glynn Harvey for their technical advice and knowledge regarding method development and instrumental analysis. We would also like to thank the volunteers for participating in the present study and Mario Siervo, Sarah Jones and Desda Jordan who assisted with the phlebotomy and volunteer study of this work. Finally, we would like to thank Ann Prentice, Susan Jebb, Gita Mishra, Mary Pennant, Sarah Casey, Adrian Izzard and Cheryl Kidney for their continued support and kind help. A. G., L. J. C. B. and W. A. C. contributed to the design of the study. A. G. performed the actual study including the meal design and preparation, volunteer work, HPLC and GC-MS analysis of the plasma and food, and data analysis. There are no conflicts of interest.

\section{References}

1. FAO (2000) The State of Food Insecurity in the World 2000. Rome: Food and Agricultutral Organisation of the United Nations.

2. Sommer A \& West KJ (1996) Vitamin A Deficiency: Health, Survival, and Vision. Oxford: Oxford University Press.

3. Gillespie S \& Mason J (1994) Nutrition Policy Discussion Paper No. 14; Controlling Vitamin A Deficiency: A Report Based on the ACC/SCN Consultative Group. Meeting on Strategies for the Control of Vitamin A Deficiency, pp. 1-81. Ottowa: United Nations UNIES, Administrative Committee on Coordination. Subcommittee on Nutrition.

4. Jackson MJ (1997) The assessment of bioavailability of micronutrients: introduction. Eur J Clin Nutr 51, S1-S2.

5. Castenmiller JJM \& West CE (1998) Bioavailability and bioconversion of carotenoids. Annu Rev Nutr 18, 19-38.

6. van Lieshout $M$, West CE \& van Breemen RB (2003) Isotopic tracer techniques for studying the bioavailability and bioefficacy of dietary carotenoids, particularly betacarotene, in humans: a review. Am J Clin Nutr 77, 12-28.

7. Kendall P (1994) Freezing Vegetables. Fort Collins, CO: Colorado State University.

8. Desobry SA, Netto FM \& Labuza TP (1998) Preservation of beta-carotene from carrots. Crit Rev Food Sci Nutr 38, 381-396.

9. Hart DJ \& Scott KJ (1995) Development and evaluation of an HPLC method for the analysis of carotenoids in foods, and the measurement of the carotenoid content of vegetables and fruits commonly consumed in the UK. Food Chem $\mathbf{5 4}$, $101-111$.

10. Yao LH, Liang YX, Trahanovsky WS, et al. (2000) Use of a C-13 tracer to quantify the plasma appearance of a physiological dose of lutein in humans. Lipids 35, 339-348.

11. Parker RS, Brenna JT \& Swanson JE (1997) Assessing metabolism of beta-[C-13]carotene using high-precision isotope ratio mass spectrometry. Methods Enzymol 282, 130-140.

12. Bluck LJC \& Coward WA (1997) Peak measurement in gas chromatographic mass spectrometric isotope studies. J Mass Spectrom 32, 1212-1218.

13. Bluck L \& Volmer DA (2008) The role of naturally occurring stable isotopes in mass spectrometry, part I: the theory. Spectroscopy 23, 36-43.

14. Bohlke JK, de Laeter JR, De Bievre P, et al. (2001) Isotopic compositions of the elements. 2001. J Phys Chem Ref Data 34, 57-67.

15. Thurnham DI, Smith E \& Flora PS (1988) Concurrent liquidchromatographic assay of retinol, alpha-tocopherol, betacarotene, alpha-carotene, lycopene, and beta-cryptoxanthin in plasma, with tocopherol acetate as internal standard. Clin Chem 34, 377-381.

16. Thomas JB, Kline MC, Gill LM, et al. (2001) Preparation and value assignment of standard reference material 968c fat-soluble vitamins, carotenoids, and cholesterol in human serum. Clin Chim Acta 305, 141-155.

17. Knapp DR (1979) Handbook of Analytical Derivatization Reactions. New York: John Wiley \& Sons.

18. Haycock G, Schwartz G \& Wisotsky D (1978) Geometric method for measuring body surface area: a height-weight 
formula validated in infants, children and adults. $J$ Pediatr 93, 62-66.

19. Hurley PJ (1975) Red cell and plasma volumes in normal adults. J Nucl Med 16, 46-52.

20. Agency FS (2002) McCance and Widdowson's The Composition of Foods, 6th ed. Cambridge: Royal Society of Chemistry.

21. Novotny JA, Dueker SR, Zech LA, et al. (1995) Compartmental analysis of the dynamics of beta-carotene metabolism in an adult volunteer. J Lipid Res 36, 1825-1838.

22. Koushik A, Hunter DJ, Spiegelman D, et al. (2006) Intake of the major carotenoids and the risk of epithelial ovarian cancer in a pooled analysis of 10 cohort studies. Int J Cancer 119, 2148-2154.

23. Haskell MJ (1998) Plasma kinetics of an oral dose of [H-2(4)] retinyl acetate in human subjects with estimated low or high total body stores of vitamin A. Am J Clin Nutr 68, 90-95.

24. Bitzen U, Winqvist M, Nilssonehle P, et al. (1994) Retinyl palmitate is a reproducible marker for chylomicron elimination from blood. Scand J Clin Lab Invest 54, 611-613.

25. FAO (1967) Requirements of vitamin A, thiamine, riboflavin and niacin. FAO Nutr Meet Rep Ser 42, 1-114.

26. NRC (1989) NRC (National Reserach Council) Report of the Subcommittee on Recommended Dietary Allowances, 10th ed. Washington, DC: National Academy Press.

27. Bieri JG \& McKenna MC (1981) Expressing dietary values for fat-soluble vitamins - changes in concepts and terminology. Am J Clin Nutr 34, 289-295.

28. Hume EM \& Krebs HA (1949) Vitamin A Requirement of Human Adult. An Experimental Study of Vitamin A Deprivation in Man. A Report of the Vitamin A Sub-Committee of the Accessory Food factors Committee. London: Medical Research Council pp. 145.

29. Institute of Medicine (2001) Dietary Reference Intakes for Vitamin A, Vitamin K, Arsenic, Boron, Chromium, Copper, Iodine, Iron, Manganese, Molybdenum, Nickel, Silicon, Vanadium, and Zinc. Washington, DC: National Academy Press.

30. de Pee S, West CE, Muhilal D, et al. (1995) Lack of improvement in vitamin-A status with increased consumption of dark-green leafy vegetables. Lancet 346, 75-81.

31. de Pee S, West CE, Permaesih D, et al. (1998) Orange fruit is more effective than are dark-green, leafy vegetables in increasing serum concentrations of retinol and beta-carotene in schoolchildren in Indonesia. Am J Clin Nutr 68, 1058-1067.

32. Parker RS, Swanson JE, You CS, et al. (1999) Bioavailability of carotenoids in human subjects. Proc Nutr Soc 58, $155-162$.

33. van het Hof KH, de Boer BCJ, Tijburg LBM, et al. (2000) Carotenoid bioavailability in humans from tomatoes processed in different ways determined from the carotenoid response in the triglyceride-rich lipoprotein fraction of plasma after a single consumption and in plasma after four days of consumption. J Nutr 130, 1189-1196.

34. van het Hof KH, West CE, Weststrate JA, et al. (2002) Dietary factors that affect the bioavailability of carotenoids. J Nutr 132, 503-506.

35. Tang GW, Qin J, Dolnikowski GG, et al. (2005) Spinach or carrots can supply significant amounts of vitamin A as assessed by feeding with intrinsically deuterated vegetables. Am J Clin Nutr 82, 821-828.

36. de Pee S \& West CE (1996) Dietary carotenoids and their role in combating vitamin A deficiency: a review of the literature. Eur J Clin Nutr 50, S38-S53.

37. Haskell MJ, Jamil KM, Hassan F, et al. (2004) Daily consumption of Indian spinach (Basella alba) or sweet potatoes has a positive effect on total-body vitamin A stores in Bangladeshi men. Am J Clin Nutr 80, 705-714.
Appendix 1. Calculation of the enrichment of $\boldsymbol{\beta}$-carotene from GC-MS data

The cracking pattern of the molecular cluster of perhydro $\beta$-carotene can be analysed by assuming that the molecule contains two species of hydrogen, one from the native carotenoid made up of fifty-six sites with fractional abundance $F_{\mathrm{a}}$, and the other added in the hydrogenation comprising twenty-two sites at abundance $F_{\mathrm{b}}$, in addition to the carbon with abundance $F_{\mathrm{C}}$. Elementary permutation and combination theory ${ }^{(13)}$ gives the theoretical intensity of each isotopologue of the compound as:

$$
\begin{aligned}
\operatorname{mass} 558, A= & \left(1-F_{\mathrm{C}}\right)^{40}\left(1-F_{\mathrm{a}}\right)^{56}\left(1-F_{\mathrm{b}}\right)^{22} \\
\operatorname{mass} 559, B= & 40 \times F_{\mathrm{C}}\left(1-F_{\mathrm{C}}\right)^{39}\left(1-F_{\mathrm{a}}\right)^{56}\left(1-F_{\mathrm{b}}\right)^{22} \\
& +56 \times\left(1-F_{\mathrm{C}}\right)^{40} F_{\mathrm{a}}\left(1-F_{\mathrm{a}}\right)^{55}\left(1-F_{\mathrm{b}}\right)^{22} \\
& +40 \times F_{\mathrm{C}}\left(1-F_{\mathrm{C}}\right)^{439}\left(1-F_{\mathrm{a}}\right)^{56}\left(1-F_{\mathrm{b}}\right)^{22}
\end{aligned}
$$$$
\operatorname{mass} 560, C=\frac{40 \times 39}{2} \times F_{\mathrm{C}}^{2}\left(1-F_{\mathrm{C}}\right)^{38}\left(1-F_{\mathrm{a}}\right)^{56}\left(1-F_{\mathrm{b}}\right)^{22}
$$$$
+40 \times 56 \times F_{\mathrm{C}}\left(1-F_{\mathrm{C}}\right)^{39} F_{\mathrm{a}}\left(1-F_{\mathrm{a}}\right)^{55}\left(1-F_{\mathrm{b}}\right)^{22}
$$$$
+40 \times 22 \times F_{\mathrm{C}}\left(1-F_{\mathrm{C}}\right)^{39}\left(1-F_{\mathrm{a}}\right)^{56} F_{\mathrm{b}}\left(1-F_{\mathrm{b}}\right)^{21}
$$$$
+\frac{56 \times 55}{2} \times\left(1-F_{\mathrm{C}}\right)^{40} F_{\mathrm{a}}^{2}\left(1-F_{\mathrm{a}}\right)^{54}\left(1-F_{\mathrm{b}}\right)^{22}
$$$$
+56 \times 22 \times\left(1-F_{\mathrm{C}}\right)^{40} F_{\mathrm{a}}\left(1-F_{\mathrm{a}}\right)^{55} F_{\mathrm{b}}\left(1-F_{\mathrm{b}}\right)^{21}
$$$$
+\frac{22 \times 21}{2} \times\left(1-F_{\mathrm{C}}\right)^{40}\left(1-F_{\mathrm{a}}\right)^{56} F_{\mathrm{b}}^{2}\left(1-F_{\mathrm{b}}\right)^{20}
$$

mass 561,

$$
\begin{aligned}
& D=\frac{40 \times 39 \times 38}{2 \times 3} \times F_{\mathrm{C}}^{3}\left(1-F_{\mathrm{C}}\right)^{37}\left(1-F_{\mathrm{a}}\right)^{56}\left(1-F_{\mathrm{b}}\right)^{22} \\
& +\frac{40 \times 39 \times 56}{2} \times F_{\mathrm{C}}^{2}\left(1-F_{\mathrm{C}}\right)^{38} F_{\mathrm{a}}\left(1-F_{\mathrm{a}}\right)^{55}\left(1-F_{\mathrm{b}}\right)^{22} \\
& +\frac{40 \times 39 \times 22}{2} \times F_{\mathrm{C}}^{2}\left(1-F_{\mathrm{C}}\right)^{38}\left(1-F_{\mathrm{a}}\right)^{56} F_{\mathrm{b}}\left(1-F_{\mathrm{b}}\right)^{21} \\
& +\frac{40 \times 56 \times 55}{2} \times F_{\mathrm{C}}\left(1-F_{\mathrm{C}}\right)^{39} F_{\mathrm{a}}^{2}\left(1-F_{\mathrm{a}}\right)^{54}\left(1-F_{\mathrm{b}}\right)^{22} \\
& +40 \times 56 \times 22 \times F_{\mathrm{C}}\left(1-F_{\mathrm{C}}\right)^{39} F_{\mathrm{a}}\left(1-F_{\mathrm{a}}\right)^{55} F_{\mathrm{b}}\left(1-F_{\mathrm{b}}\right)^{21} \\
& +\frac{40 \times 22 \times 21}{2} \times F_{\mathrm{C}}\left(1-F_{\mathrm{C}}\right)^{39}\left(1-F_{\mathrm{a}}\right)^{56} F_{\mathrm{b}}^{2}\left(1-F_{\mathrm{b}}\right)^{20} \\
& +\frac{56 \times 55 \times 54}{2 \times 3} \times\left(1-F_{\mathrm{C}}\right)^{40} F_{\mathrm{a}}^{3}\left(1-F_{\mathrm{a}}\right)^{53}\left(1-F_{\mathrm{b}}\right)^{22} \\
& +\frac{56 \times 55 \times 22}{2} \times\left(1-F_{\mathrm{C}}\right)^{40} F_{\mathrm{a}}^{2}\left(1-F_{\mathrm{a}}\right)^{54} F_{\mathrm{b}}\left(1-F_{\mathrm{b}}\right)^{21} \\
& +\frac{56 \times 22 \times 21}{2} \times\left(1-F_{\mathrm{C}}\right)^{40} F_{\mathrm{a}}\left(1-F_{\mathrm{a}}\right)^{55} F_{\mathrm{b}}^{2}\left(1-F_{\mathrm{b}}\right)^{20} \\
& +\frac{22 \times 21 \times 20}{2 \times 3} \times\left(1-F_{\mathrm{C}}\right)^{40}\left(1-F_{\mathrm{a}}\right)^{56} F_{\mathrm{b}}^{3}\left(1-F_{\mathrm{b}}\right)^{19}
\end{aligned}
$$


In GC-MS, there is no absolute measure of spectral intensity, and results are reported as ratios to the parent peak. Therefore,

$$
\begin{aligned}
& \frac{B}{A}=40 \times \frac{F_{\mathrm{C}}}{\left(1-F_{\mathrm{C}}\right)}+56 \times \frac{F_{\mathrm{a}}}{\left(1-F_{\mathrm{a}}\right)}+22 \times \frac{F_{\mathrm{b}}}{\left(1-F_{\mathrm{b}}\right)} \\
& \frac{C}{A}=\frac{40 \times 39}{2} \times \frac{F_{\mathrm{C}}^{2}}{\left(1-F_{\mathrm{C}}\right)^{2}}+40 \times 56 \times \frac{F_{\mathrm{C}}}{\left(1-F_{\mathrm{C}}\right)} \frac{F_{\mathrm{a}}}{\left(1-F_{\mathrm{a}}\right)} \\
& +40 \times 22 \times \frac{F_{\mathrm{C}}}{\left(1-F_{\mathrm{C}}\right)} \frac{F_{\mathrm{b}}}{\left(1-F_{\mathrm{b}}\right)}+\frac{56 \times 55}{2} \times \frac{F_{\mathrm{a}}^{2}}{\left(1-F_{\mathrm{a}}\right)^{2}} \\
& +56 \times 22 \times \frac{F_{\mathrm{a}}}{\left(1-F_{\mathrm{a}}\right)} \frac{F_{\mathrm{b}}}{\left(1-F_{\mathrm{b}}\right)}+\frac{22 \times 21}{2} \times \frac{F_{\mathrm{b}}^{2}}{\left(1-F_{\mathrm{b}}\right)^{2}} \\
& \frac{D}{A}=\frac{40 \times 39 \times 38}{2 \times 3} \times \frac{F_{\mathrm{C}}^{3}}{\left(1-F_{\mathrm{C}}\right)^{3}}+\frac{40 \times 39 \times 56}{2} \times \frac{F_{\mathrm{C}}^{2}}{\left(1-F_{\mathrm{C}}\right)^{2}} \frac{F_{\mathrm{a}}}{\left(1-F_{\mathrm{a}}\right)} \\
& +\frac{40 \times 39 \times 22}{2} \times \frac{F_{\mathrm{C}}^{2}}{\left(1-F_{\mathrm{C}}\right)^{2}} \frac{F_{\mathrm{b}}}{\left(1-F_{\mathrm{b}}\right)}+\frac{40 \times 56 \times 55}{2} \\
& \times \frac{F_{\mathrm{C}}}{\left(1-F_{\mathrm{C}}\right)} \frac{F_{\mathrm{a}}^{2}}{\left(1-F_{\mathrm{a}}\right)^{2}}+40 \times 56 \times 22 \times \frac{F_{\mathrm{C}}}{\left(1-F_{\mathrm{C}}\right)} \frac{F_{\mathrm{a}}}{\left(1-F_{\mathrm{a}}\right)} \frac{F_{\mathrm{b}}}{\left(1-F_{\mathrm{b}}\right)} \\
& +\frac{40 \times 22 \times 21}{2} \times \frac{F_{\mathrm{C}}}{\left(1-F_{\mathrm{C}}\right)} \frac{F_{\mathrm{b}}^{2}}{\left(1-F_{\mathrm{b}}\right)^{2}}+\frac{56 \times 55 \times 54}{2 \times 3} \\
& \times \frac{F_{\mathrm{a}}^{3}}{\left(1-F_{\mathrm{a}}\right)^{3}}+\frac{56 \times 55 \times 22}{2} \times \frac{F_{\mathrm{a}}^{2}}{\left(1-F_{\mathrm{a}}\right)^{2}} \frac{F_{\mathrm{b}}}{\left(1-F_{\mathrm{b}}\right)}+\frac{56 \times 22 \times 21}{2} \\
& \times \frac{F_{\mathrm{a}}}{\left(1-F_{\mathrm{a}}\right)} \frac{F_{\mathrm{b}}^{2}}{\left(1-F_{\mathrm{b}}\right)^{2}}+\frac{22 \times 21 \times 20}{2 \times 3} \times \frac{F_{\mathrm{b}}^{3}}{\left(1-F_{\mathrm{b}}\right)^{3}}
\end{aligned}
$$

If carbon and b-hydrogens are at natural abundance $\left(F_{\mathrm{C}}=0.0111 \text { and } F_{\mathrm{b}}=0.00015\right)^{(14)}$, then these become:

$$
\begin{aligned}
\frac{\mathrm{B}}{A} & =0.45228+56 \times \frac{F_{\mathrm{a}}}{\left(1-F_{\mathrm{a}}\right)} \\
\frac{C}{A}= & 0.09976+25.3279 \times \frac{F_{\mathrm{a}}}{\left(1-F_{\mathrm{a}}\right)}+1540 \frac{F_{\mathrm{a}}^{2}}{\left(1-F_{\mathrm{a}}\right)^{2}} \\
\frac{D}{A}= & 0.01430+5.5866 \frac{F_{\mathrm{a}}}{\left(1-F_{\mathrm{a}}\right)}+696.5177 \frac{F_{\mathrm{a}}^{2}}{(1-F)^{2}} \\
& +27720 \frac{F_{\mathrm{a}}^{3}}{\left(1-F_{\mathrm{a}}\right)^{3}}
\end{aligned}
$$

The best estimate of $F_{\mathrm{a}}$ can now be obtained by least squares fitting to the experimentally observed mass spectral ratios.

\section{Appendix 2. Calculation of $\boldsymbol{\beta}$-carotene mole fractions in} plasma

The contributions to the mass spectra in the range $558-580 \mathrm{~m} / \mathrm{z}$ are summarized in Table 1 . From this, it is possible to derive expressions for the six isotopomer ratios measured with respect to the peak at $558 \mathrm{~m} / \mathrm{z}$

$$
\begin{aligned}
& R_{559}=\frac{\left(1-X_{\mathrm{Y}}-X_{\mathrm{C}}\right) B_{\mathrm{U}}+X_{\mathrm{Y}} B_{\mathrm{Y}}}{\left(1-X_{\mathrm{Y}}-X_{\mathrm{C}}\right) A_{\mathrm{U}}+X_{\mathrm{Y}} A_{\mathrm{Y}}} \\
& R_{560}=\frac{\left(1-X_{\mathrm{Y}}-X_{\mathrm{C}}\right) C_{\mathrm{U}}+X_{\mathrm{Y}} C_{\mathrm{Y}}}{\left(1-X_{\mathrm{Y}}-X_{\mathrm{C}}\right) A_{\mathrm{U}}+X_{\mathrm{Y}} A_{\mathrm{Y}}} \\
& R_{561}=\frac{\left(1-X_{\mathrm{Y}}-X_{\mathrm{C}}\right) D_{\mathrm{U}}+X_{\mathrm{Y}} D_{\mathrm{Y}}}{\left(1-X_{\mathrm{Y}}-X_{\mathrm{C}}\right) A_{\mathrm{U}}+X_{\mathrm{Y}} A_{\mathrm{Y}}} \\
& R_{578}=\frac{X_{\mathrm{C}} A_{\mathrm{C}}}{\left(1-X_{\mathrm{Y}}-X_{\mathrm{C}}\right) A_{\mathrm{U}}+X_{\mathrm{Y}} A_{\mathrm{Y}}} \\
& R_{579}=\frac{X_{\mathrm{C}} B_{\mathrm{C}}}{\left(1-X_{\mathrm{Y}}-X_{\mathrm{C}}\right) A_{\mathrm{U}}+X_{\mathrm{Y}} A_{\mathrm{Y}}} \\
& R_{580}=\frac{X_{\mathrm{C}} C_{\mathrm{C}}}{\left(1-X_{\mathrm{Y}}-X_{\mathrm{C}}\right) A_{\mathrm{U}}+X_{\mathrm{Y}} A_{\mathrm{Y}}}
\end{aligned}
$$

Simple rearrangement leads to the set of six simultaneous equations:

$$
\begin{aligned}
& {\left[\left(A_{\mathrm{U}}-A_{\mathrm{Y}}\right) R_{559}-\left(B_{\mathrm{U}}-B_{\mathrm{Y}}\right)\right] X_{\mathrm{Y}}+\left(A_{\mathrm{U}} R_{559}-B_{\mathrm{U}}\right) X_{\mathrm{C}}=A_{\mathrm{U}} R_{559}-B_{\mathrm{U}}} \\
& {\left[\left(A_{\mathrm{U}}-A_{\mathrm{Y}}\right) R_{560}-\left(C_{\mathrm{U}}-C_{\mathrm{Y}}\right)\right] X_{\mathrm{Y}}+\left(A_{\mathrm{U}} R_{560}-C_{\mathrm{U}}\right) X_{\mathrm{C}}=A_{\mathrm{U}} R_{560}-C_{\mathrm{U}}} \\
& {\left[\left(A_{\mathrm{U}}-A_{\mathrm{Y}}\right) R_{561}-\left(D_{\mathrm{U}}-D_{\mathrm{Y}}\right)\right] X_{\mathrm{Y}}+\left(A_{\mathrm{U}} R_{561}-D_{\mathrm{U}}\right) X_{\mathrm{C}}=A_{\mathrm{U}} R_{561}-D_{\mathrm{U}}} \\
& \left(A_{\mathrm{U}}-A_{\mathrm{Y}}\right) R_{578} X_{\mathrm{Y}}+\left(A_{\mathrm{U}} R_{578}+A_{\mathrm{C}}\right) X_{\mathrm{C}}=A_{\mathrm{U}} R_{578} \\
& \left(A_{\mathrm{U}}-A_{\mathrm{Y}}\right) R_{579} X_{\mathrm{Y}}+\left(A_{\mathrm{U}} R_{579}+B_{\mathrm{C}}\right) X_{\mathrm{C}}=A_{\mathrm{U}} R_{579} \\
& \left(A_{\mathrm{U}}-A_{\mathrm{Y}}\right) R_{580} X_{\mathrm{Y}}+\left(A_{\mathrm{U}} R_{580}+C_{\mathrm{C}}\right) X_{\mathrm{C}}=A_{\mathrm{U}} R_{580}
\end{aligned}
$$

In the matrix form, this is written as:

$$
\begin{gathered}
{\left[\begin{array}{rr}
\left(A_{\mathrm{U}}-A_{\mathrm{Y}}\right) R_{559}-\left(B_{\mathrm{U}}-B_{\mathrm{Y}}\right) & \left(A_{\mathrm{U}} R_{559}-B_{\mathrm{U}}\right) \\
\left(A_{\mathrm{U}}-A_{\mathrm{Y}}\right) R_{560}-\left(C_{\mathrm{U}}-C_{\mathrm{Y}}\right) & \left(A_{\mathrm{U}} R_{560}-C_{\mathrm{U}}\right) \\
\left(A_{\mathrm{U}}-A_{\mathrm{Y}}\right) R_{561}-\left(D_{\mathrm{U}}-D_{\mathrm{Y}}\right) & \left(A_{\mathrm{U}} R_{561}-D_{\mathrm{U}}\right) \\
\left(A_{\mathrm{U}}-A_{\mathrm{Y}}\right) R_{578} & \left(A_{\mathrm{U}} R_{578}+A_{\mathrm{C}}\right) \\
\left(A_{\mathrm{U}}-A_{\mathrm{Y}}\right) R_{579} & \left(A_{\mathrm{U}} R_{579}+B_{\mathrm{C}}\right) \\
\left(A_{\mathrm{U}}-A_{\mathrm{Y}}\right) R_{580} & \left(A_{\mathrm{U}} R_{580}+C_{\mathrm{C}}\right)
\end{array}\right]\left[\begin{array}{c}
X_{\mathrm{Y}} \\
X_{\mathrm{C}}
\end{array}\right]} \\
=\left[\begin{array}{c}
A_{\mathrm{U}} R_{559}-B_{\mathrm{U}} \\
A_{\mathrm{U}} R_{560}-C_{\mathrm{U}} \\
A_{\mathrm{U}} R_{561}-D_{\mathrm{U}} \\
A_{\mathrm{U}} R_{578} \\
A_{\mathrm{U}} R_{579} \\
A_{\mathrm{U}} R_{580}
\end{array}\right] .
\end{gathered}
$$

This is of the form:

$$
\underline{\underline{C}} \underline{X}=\underline{H}
$$


which has the well-known least-squares solution:

$$
\underline{X}=\left(\underline{\underline{C}}^{T} \underline{\underline{C}}\right)^{-1} \underline{\underline{C}}^{T} \underline{H} .
$$

\section{Worked example}

The mass spectrum obtained from a plasma sample is:

$\begin{array}{lccccc}R_{559} & R_{560} & R_{561} & R_{578} & R_{579} & R_{580} \\ 44.541 \% & 9.881 \% & 1.604 \% & 10.940 \% & 2.692 \% & 0.331 \%\end{array}$

Previous measurements have indicated that the coefficients of spectrum of the pure components are

\begin{tabular}{lcccc}
\hline Species & $A$ & $B$ & $C$ & $D$ \\
\hline Unlabelled (U) & 0.6492 & 0.2819 & 0.0598 & 0.0082 \\
From carrots $(\mathrm{Y})$ & 0.4461 & 0.3616 & 0.1450 & 0.0384 \\
${ }^{13}$ C-labelled $(\mathrm{C})$ & 0.7828 & 0.1928 & 0.0227 & - \\
\hline
\end{tabular}

Therefore,

$$
\underline{H}=\left[\begin{array}{c}
0.6492 \times 0.44541-0.2819 \\
0.6492 \times 0.09881-0.0598 \\
0.6492 \times 0.01604-0.0082 \\
0.6492 \times 0.10940 \\
0.6492 \times 0.02692 \\
0.6492 \times 0.00331
\end{array}\right]=\left[\begin{array}{c}
0.0073 \\
0.0044 \\
0.0022 \\
0.0710 \\
0.0175 \\
0.0021
\end{array}\right]
$$

and

$[(0.6492-0.4461) \times 0 \cdot 44541-(0.2819-0.3616) 0.6492 \times 0 \cdot 44541-0.2819]$ $(0.6492-0.4461) \times 0.09881-(0.0598-0.1450) 0.6492 \times 0.09881-0.0598$ $(0.6492-0.4461) \times 0.01604-(0.0082-0.0384) 0.6492 \times 0.01604-0.0082$ $(0.6492-0.4461) \times 0.10940$ $0.6492 \times 0.10940+0.7828$ $(0.6492-0.4461) \times 0.02692$ $0 \cdot 6492 \times 0 \cdot 02692+0 \cdot 1928$ $(0 \cdot 6492-0 \cdot 4461) \times 0.00331$ $0 \cdot 6492 \times 0 \cdot 00331+0.0227$ and

$$
\left(\underline{\underline{C}}^{T} \underline{\underline{C}}\right)^{-1}=\left[\begin{array}{cc}
24.3545 & -0.6893 \\
-0.6893 & 1.3116
\end{array}\right]
$$

The pseudo-inverse of $\underline{\underline{C}}$ is then

$$
\left(\underline{\underline{C}}^{T} \underline{\underline{C}}\right)^{-1} \underline{\underline{C}}^{T}
$$

$$
=\left[\begin{array}{cccccc}
4.1392 & 2.5608 & 0.8133 & -0.0474 & -0.0118 & -0.0008 \\
-0.1078 & -0.0669 & -0.0202 & 1.1046 & 0.2720 & 0.0321
\end{array}\right] .
$$

Finally,

$$
\underline{X}=\left(\underline{\underline{C}}^{T} \underline{\underline{C}}\right)^{-1} \underline{\underline{C}} \underline{H}=\left[\begin{array}{l}
0.0394 \\
0.0822
\end{array}\right]
$$

Meaning that the $\beta$-carotene comprised $87 \cdot 8 \%$ pre-existing (unlabelled), $3.9 \%$ from the carrots and $8.2 \%$ from the ${ }^{13} \mathrm{C}$-labelled standard.

\section{Appendix 3. Calculation of retinol mole fractions in plasma}

The contributions to the mass spectra in the range $358-371 \mathrm{~m} / z$ are summarized in Table 2 . From this, it is possible to derive expressions for the six isotopomer ratios measured with respect to the peak at $558 \mathrm{~m} / z$ :

$$
\begin{aligned}
& R_{359}=\frac{\left(1-X_{\mathrm{Y}}-X_{\mathrm{C}}-X_{\mathrm{D}}\right) B_{\mathrm{U}}+X_{\mathrm{Y}} B_{\mathrm{Y}}}{\left(1-X_{\mathrm{Y}}-X_{\mathrm{C}}-X_{\mathrm{D}}\right) A_{\mathrm{U}}+X_{\mathrm{Y}} A_{\mathrm{Y}}} \\
& R_{360}=\frac{\left(1-X_{\mathrm{Y}}-X_{\mathrm{C}}-X_{\mathrm{D}}\right) C_{\mathrm{U}}+X_{\mathrm{Y}} C_{\mathrm{Y}}}{\left(1-X_{\mathrm{Y}}-X_{\mathrm{C}}-X_{\mathrm{D}}\right) A_{\mathrm{U}}+X_{\mathrm{Y}} A_{\mathrm{Y}}} \\
& R_{361}=\frac{\left(1-X_{\mathrm{Y}}-X_{\mathrm{C}}-X_{\mathrm{D}}\right) D_{\mathrm{U}}+X_{\mathrm{Y}} d_{\mathrm{Y}}}{\left(1-X_{\mathrm{Y}}-X_{\mathrm{C}}-X_{\mathrm{D}}\right) A_{\mathrm{U}}+X_{\mathrm{Y}} A_{\mathrm{Y}}} \\
& R_{362}=\frac{X_{\mathrm{D}} A_{\mathrm{D}}}{\left(1-X_{\mathrm{Y}}-X_{\mathrm{C}}-X_{\mathrm{D}}\right) A_{\mathrm{U}}+X_{\mathrm{Y}} A_{\mathrm{Y}}}
\end{aligned}
$$

Therefore,

$$
\underline{\underline{C}}^{T} \underline{\underline{C}}=\left[\begin{array}{ll}
0.0417 & 0.0219 \\
0.0219 & 0.7739
\end{array}\right]
$$

$$
\begin{aligned}
& R_{363}=\frac{X_{\mathrm{D}} B_{\mathrm{D}}}{\left(1-X_{\mathrm{Y}}-X_{\mathrm{C}}-X_{\mathrm{D}}\right) A_{\mathrm{U}}+X_{\mathrm{Y}} A_{\mathrm{Y}}} \\
& R_{364}=\frac{X_{\mathrm{D}} C_{\mathrm{D}}}{\left(1-X_{\mathrm{Y}}-X_{\mathrm{C}}-X_{\mathrm{D}}\right) A_{\mathrm{U}}+X_{\mathrm{Y}} A_{\mathrm{Y}}}
\end{aligned}
$$




$$
\begin{aligned}
& R_{365}=\frac{X_{\mathrm{D}} D_{\mathrm{D}}}{\left(1-X_{\mathrm{Y}}-X_{\mathrm{C}}-X_{\mathrm{D}}\right) A_{\mathrm{U}}+X_{\mathrm{Y}} A_{\mathrm{Y}}} \\
& R_{368}=\frac{X_{\mathrm{C}} A_{\mathrm{C}}}{\left(1-X_{\mathrm{Y}}-X_{\mathrm{C}}-X_{\mathrm{D}}\right) A_{\mathrm{U}}+X_{\mathrm{Y}} A_{\mathrm{Y}}} \\
& R_{369}=\frac{X_{\mathrm{C}} B_{\mathrm{C}}}{\left(1-X_{\mathrm{Y}}-X_{\mathrm{C}}-X_{\mathrm{D}}\right) A_{\mathrm{U}}+X_{\mathrm{Y}} A_{\mathrm{Y}}} \\
& R_{370}=\frac{X_{\mathrm{C}} C_{\mathrm{C}}}{\left(1-X_{\mathrm{Y}}-X_{\mathrm{C}}-X_{\mathrm{D}}\right) A_{\mathrm{U}}+X_{\mathrm{Y}} A_{\mathrm{Y}}} \\
& R_{371}=\frac{X_{\mathrm{C}} D_{\mathrm{C}}}{\left(1-X_{\mathrm{Y}}-X_{\mathrm{C}}-X_{\mathrm{D}}\right) A_{\mathrm{U}}+X_{\mathrm{Y}} A_{\mathrm{Y}}} .
\end{aligned}
$$

Simple rearrangement leads to the set of eleven simultaneous equations:

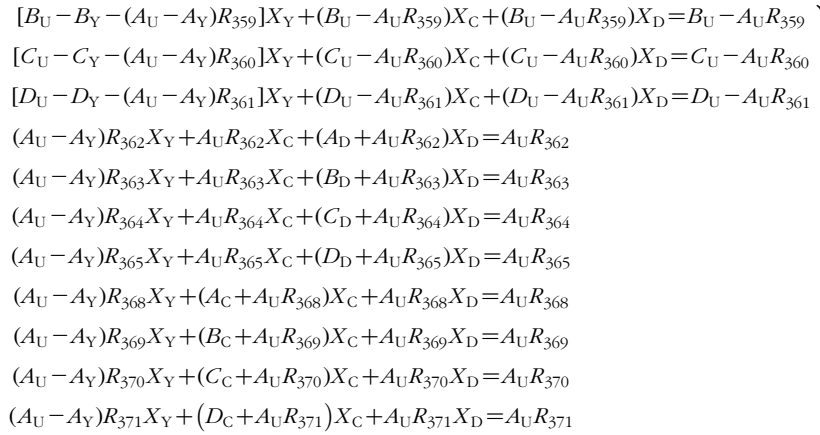

In the matrix form, this is written as

$$
\begin{aligned}
& {\left[\begin{array}{ccc}
{\left[B_{\mathrm{U}}-B_{\mathrm{Y}}-\left(A_{\mathrm{U}}-A_{\mathrm{Y}}\right) R_{359}\right]} & \left(B_{\mathrm{U}}-A_{\mathrm{U}} R_{359}\right) & \left(B_{\mathrm{U}}-A_{\mathrm{U}} R_{359}\right) \\
{\left[C_{\mathrm{U}}-C_{\mathrm{Y}}-\left(A_{\mathrm{U}}-A_{\mathrm{Y}}\right) R_{360}\right]} & \left(C_{\mathrm{U}}-A_{\mathrm{U}} R_{360}\right) & \left(C_{\mathrm{U}}-A_{\mathrm{U}} R_{360}\right) \\
{\left[D_{\mathrm{U}}-D_{\mathrm{Y}}-\left(A_{\mathrm{U}}-A_{\mathrm{Y}}\right) R_{361}\right]} & \left(D_{\mathrm{U}}-A_{\mathrm{U}} R_{361}\right) & \left(D_{\mathrm{U}}-A_{\mathrm{U}} R_{361}\right) \\
\left(A_{\mathrm{U}}-A_{\mathrm{Y}}\right) R_{362} & A_{\mathrm{U}} R_{362} & \left(A_{\mathrm{D}}+A_{\mathrm{U}} R_{362}\right) \\
\left(A_{\mathrm{U}}-A_{\mathrm{Y}}\right) R_{363} & A_{\mathrm{U}} R_{363} & \left(B_{\mathrm{D}}+A_{\mathrm{U}} R_{363}\right) \\
\left(A_{\mathrm{U}}-A_{\mathrm{Y}}\right) R_{364} & A_{\mathrm{U}} R_{364} & \left(C_{\mathrm{D}}+A_{\mathrm{U}} R_{364}\right) \\
\left(A_{\mathrm{U}}-A_{\mathrm{Y}}\right) R_{365} & A_{\mathrm{U}} R_{365} & \left(D_{\mathrm{D}}+A_{\mathrm{U}} R_{365}\right) \\
\left(A_{\mathrm{U}}-A_{\mathrm{Y}}\right) R_{368} & \left(A_{\mathrm{C}}+A_{\mathrm{U}} R_{368}\right) & A_{\mathrm{U}} R_{368} \\
\left(A_{\mathrm{U}}-A_{\mathrm{Y}}\right) R_{369} & \left(B_{\mathrm{C}}+A_{\mathrm{U}} R_{369}\right) & A_{\mathrm{U}} R_{369} \\
\left(A_{\mathrm{U}}-A_{\mathrm{Y}}\right) R_{370} & \left(C_{\mathrm{C}}+A_{\mathrm{U}} R_{370}\right) & A_{\mathrm{U}} R_{370} \\
\left(A_{\mathrm{U}}-A_{\mathrm{Y}}\right) R_{371} & \left(D_{\mathrm{C}}+A_{\mathrm{U}} R_{371}\right) & A_{\mathrm{U}} R_{371}
\end{array}\right]} \\
& {\left[\begin{array}{c}
X_{\mathrm{Y}} \\
X_{\mathrm{C}} \\
X_{\mathrm{D}}
\end{array}\right]=\left[\begin{array}{c}
B_{\mathrm{U}}-A_{\mathrm{U}} R_{359} \\
C_{\mathrm{U}}-A_{\mathrm{U}} R_{360} \\
D_{\mathrm{U}}-A_{\mathrm{U}} R_{361} \\
A_{\mathrm{U}} R_{362} \\
A_{\mathrm{U}} R_{573} \\
A_{\mathrm{U}} R_{364} \\
A_{\mathrm{U}} R_{364} \\
A_{\mathrm{U}} R_{365} \\
A_{\mathrm{U}} R_{369} \\
A_{\mathrm{U}} R_{370} \\
A_{\mathrm{U}} R_{371}
\end{array}\right]}
\end{aligned}
$$

This is of the form:

$$
\underline{\underline{C}} \underline{X}=\underline{H}
$$

which has the well-known least-squares solution:

$$
\underline{X}=\left(\underline{\underline{C}}^{T} \underline{\underline{C}}\right)^{-1} \underline{\underline{C}}^{T} \underline{H} .
$$

